\title{
THE EFFECTS OF MICRO-OSTEOPERFORATIONS ON TOOTH MOVEMENT AND BONE IN THE BEAGLE MAXILLA
}

\author{
A Thesis \\ by \\ CHRIS L. CRAMER \\ Submitted to the Office of Graduate and Professional Studies of \\ Texas A\&M University \\ in partial fulfillment of the requirements for the degree of \\ MASTER OF SCIENCE
}

\begin{abstract}
Chair of Committee, Peter H. Buschang Committee Members, Phillip M. Campbell Larry P. Tadlock Lynne A. Opperman

Head of Department, Larry L. Bellinger
\end{abstract}

May 2016

Major Subject: Oral Biology

Copyright 2016 Chris L. Cramer 


\begin{abstract}
Introduction: The purpose of this study was to determine how microosteoperforations (MOPs) affect tooth movements and bone characteristics, including bone turnover, bone density, and bone volume. Methods: A split-mouth design with 7 beagle dogs was used to evaluate bone surrounding maxillary second premolars that had been retracted for 7 weeks. The maxillary third premolars were extracted and, after 1 month of healing, 8 MOPs (1.5 mm wide and $7 \mathrm{~mm}$ deep created with the PROPEL device) were placed without flaps around the experimental side maxillary second premolars. The maxillary second premolars were retracted bilaterally with $200 \mathrm{~g}$ nickeltitanium closed coil springs. Tooth movements were measured intraorally and radiographically. Microcomputed tomography analysis was used to evaluate the material density and bone volume fraction of bone adjacent to the moving teeth. Hematoxylin and eosin sections and fluorescent sections were used to examine the bone. Results: Overall tooth movements were slightly greater on the MOP side, but neither the intraoral tooth movement measurements nor radiographic tooth movement measurements showed statistically significant $(\mathrm{p}=0.866, \mathrm{p}=0.528)$ differences. There also were no statistically significant differences in bone density $(p=0.237)$ and bone volume fraction $(p=0.398)$. Fluorescent image and histologic evaluations also showed no apparent differences near the tooth being moved. Bone healing was evident in and near the MOP sites, which had nearly, but not completely repaired by 7 weeks. Regions of acellular bone were evident extending approximately $0.8 \mathrm{~mm}$ from the MOP sites. Conclusions: The extent of MOPs
\end{abstract}


effects on tooth movements are limited. MOPs placed $3 \mathrm{~mm}$ away do not increase tooth movements and have little or no effect on bone adjacent to the tooth being moved. 


\section{DEDICATION}

This work is dedicated to my wife, Kelley, and our twin daughters, Kerry and Courtney, for their constant love, encouragement, and support. 


\section{ACKNOWLEDGEMENTS}

I would like to thank my committee chair, Dr. Peter Buschang, and my committee members, Dr. Campbell, Dr. Tadlock, and Dr. Opperman, for their insight into the complexities of research, orthodontics, and bone biology. I would also like to thank Gerald Hill for his tireless support and excellent animal care. I also appreciate Connie Tillberg's support with histology slide preparation and Ying Liu's and Edward Lee's assistance with the microcomputed tomography scans and analysis. I would also like to thank my co-residents Lauren VanGemert and Kristina Christoph for their support in brainstorming solutions to issues we encountered together and for helping each other learn the various techniques required to build appliances, perform histological scans, and the myriad other skills required throughout our respective animal research projects. Finally, I appreciate my Class of 2016 classmates Dannee Geshay, Kim Rogers, and Alec Rice for their contributions to my education for the last three years and for the next thirty or so as we master the art and science of orthodontics together. 


\section{NOMENCLATURE}

$\begin{array}{ll}\mathrm{H}+\mathrm{E} & \text { Hematoxylin and Eosin } \\ \mu \mathrm{CT} & \text { Microcomputed Tomography } \\ \mathrm{MOP} & \text { Micro-osteoperforation } \\ \text { RAP } & \text { Regional Acceleratory Phenomena }\end{array}$




\section{TABLE OF CONTENTS}

Page

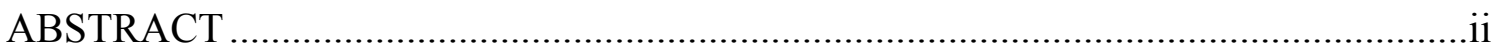

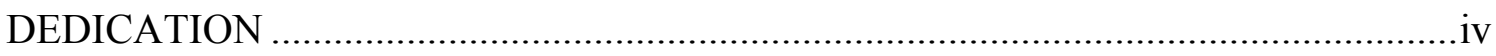

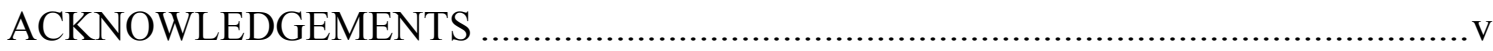

NOMENCLATURE .......................................................................................... vi

TABLE OF CONTENTS ..........................................................................................vii

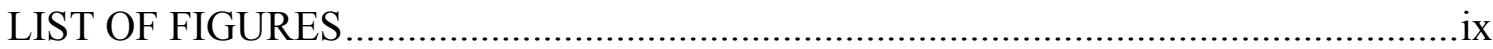

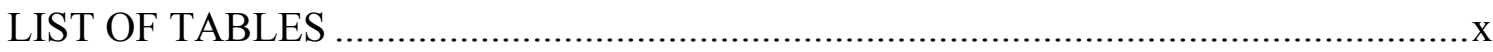

CHAPTER I INTRODUCTION AND LITERATURE REVIEW ............................... 1

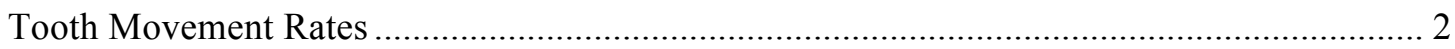

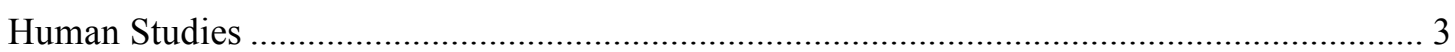

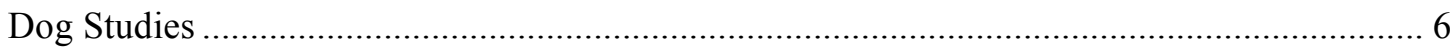

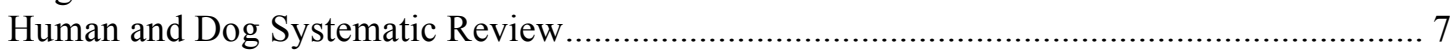

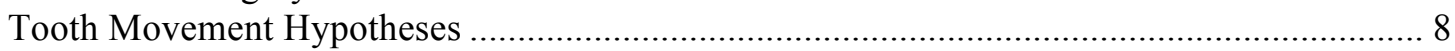

Effect of Bone Remodeling Rates and Density on Tooth Movement................................... 10

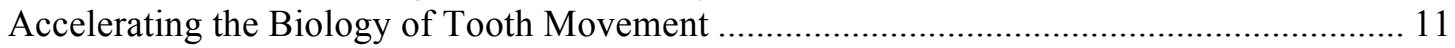

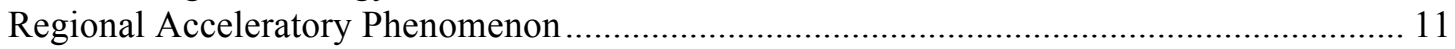

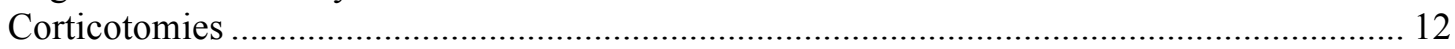

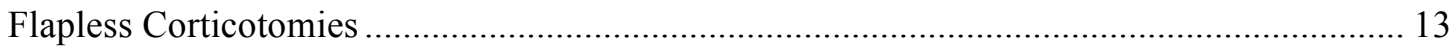

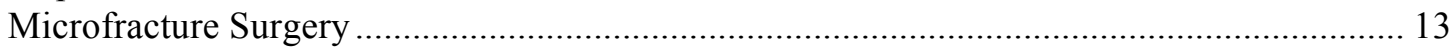

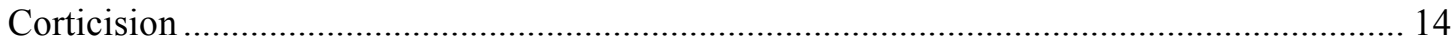

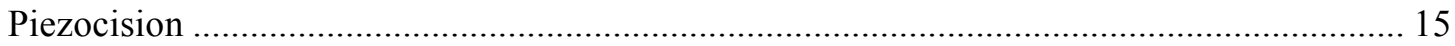

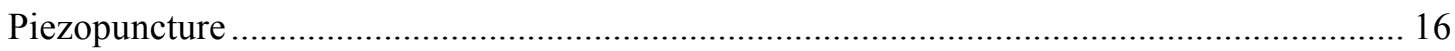

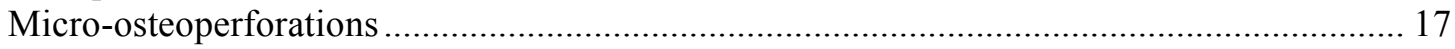

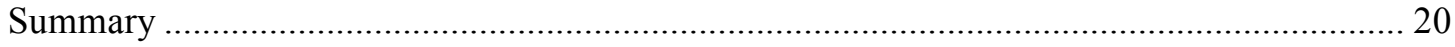

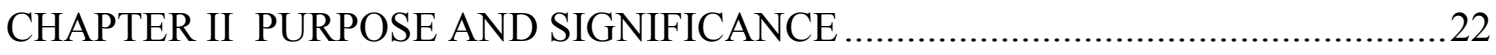

CHAPTER III MATERIALS AND METHODS .........................................................25

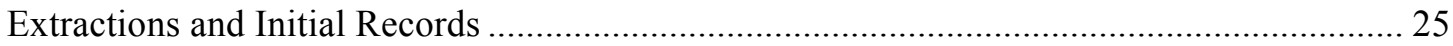

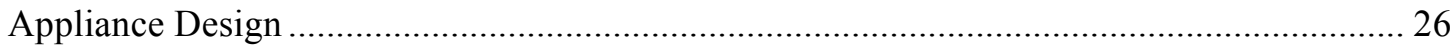

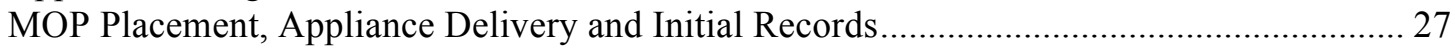

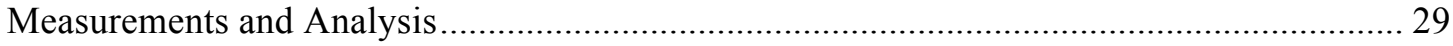




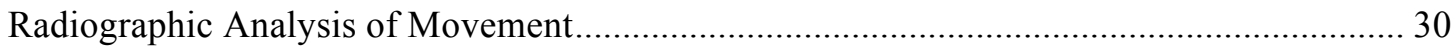

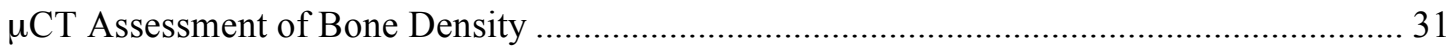

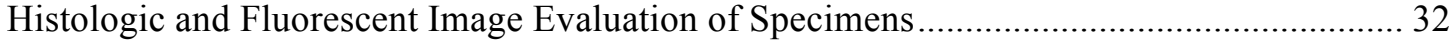

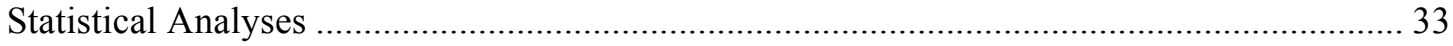

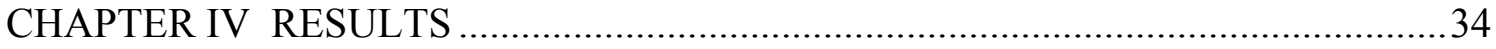

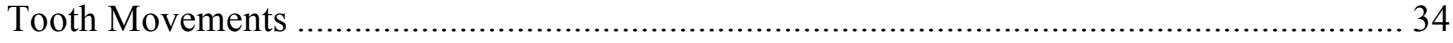

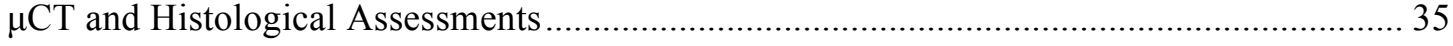

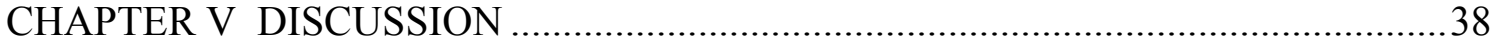

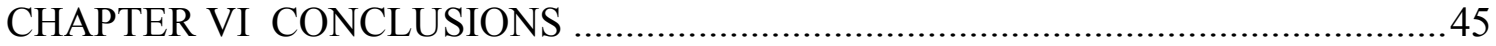

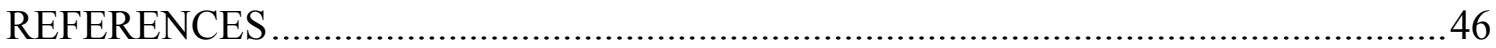

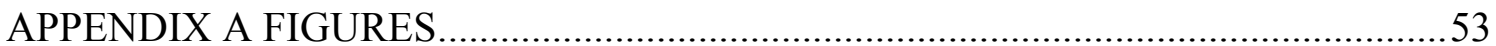

APPENDIX B MAXILLARY CANINE TIPPING CALCULATION..........................61 


\section{LIST OF FIGURES}

Page

Figure 1. Cephalostat diagram and a series of radiographs .........................53

Figure 2. Appliance design and MOP placement.............................53

Figure 3. Radiographic MOP placement.................................54

Figure 4. Radiographic analysis points and dimensions......................54

Figure 5. $\quad$ MOP locations and $\mu \mathrm{CT}$ volume of interest..........................55

Figure 6. Intraoral caliper measurements of P2-P4 space closure...............55

Figure 7. Radiographic measurements of P2-P4 space closure.................56

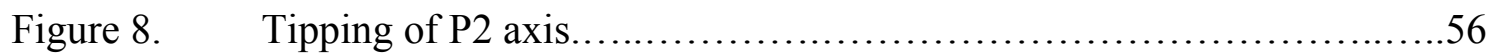

Figure 9. Adjacent alveolar bone density..................................57

Figure 10. Adjacent alveolar bone volume fraction $(\mathrm{BV} / \mathrm{TV}) \ldots \ldots \ldots \ldots \ldots \ldots \ldots \ldots$

Figure 11. Control side $\mathrm{H}+\mathrm{E}$ sections.......................................

Figure 12. Experimental side $\mathrm{H}+\mathrm{E}$ sections....................................

Figure 13. Control side second premolar with magnification of bone front ........59

Figure 14. Control and experimental fluorescent sections.....................59

Figure 15. Magnified MOP fluorescent section............................60

Figure 16. Tipping calculation for Mx Canine..............................60 


\section{LIST OF TABLES}

Page

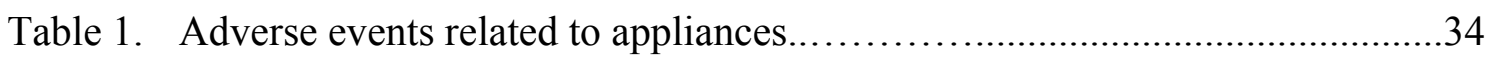




\section{CHAPTER I}

\section{INTRODUCTION AND LITERATURE REVIEW}

Depending on case complexity, the duration of most comprehensive orthodontic treatments range from one to three years. More specifically, non-extraction cases require 21-27 months and extraction cases require 25-35 months. ${ }^{1}$ Numerous factors influence treatment times, including the orthodontic mechanics employed, patient cooperation, and, particularly in extraction cases, the distance that teeth must be moved. ${ }^{2-4}$

Prolonged orthodontic treatment time is problematic. It increases the risk of root

resorption, ${ }^{5,6}$ decalcification, ${ }^{7}$ and periodontal problems. ${ }^{8}$ Orthodontic research seeks to minimize these risks by developing methods to reduce treatment time, while still providing uncompromised treatment results.

In search of faster tooth movements, researchers have evaluated various force levels, continuous verses discontinuous forces, different bracket systems, miniscrew anchorage, and various other orthodontic mechanics in an effort to optimize tooth movements. They have also studied pharmacological approaches to inducing faster tooth movements by increasing bone turnover and decreased bone density. Another extensively researched approach of increasing tooth movements is through a corticotomy procedure, and intentional surgical insult to the periodontium to induce the regional acceleratory phenomenon (RAP); corticotomies increase bone turnover and decrease bone density with the result of increasing tooth movement rates by two or more times normal rates for more extensive procedures. Surgical insults have ranged from full flap 
and alveolar decortication to raising a flap alone to less invasive flapless procedures; because the RAP is proportional to the amount of injury, the results vary from significant changes in tooth movements to little or no differences with approaches inducing less injury.

Researchers have used different animal models, including mice, rats, cats, dogs, and humans. Dogs are particularly useful for studying different orthodontic forces and mechanics due to their similarity in alveolar and tooth structure to humans ${ }^{9,10}$ and the fact that histological studies can be conducted on dogs that are not possible in humans. Through a systematic review of the dog and human literature relative to orthodontic tooth movements, a wide range of clinically applicable forces has been demonstrated, which incidentally are similar between dogs and humans. ${ }^{11}$

The following section surveys the orthodontic literature including different animal and human studies that have evaluated orthodontic mechanics, pharmacological effects, and several different corticotomy procedures. Also included are a discussion of tooth movement rates and the biology of tooth movement.

Tooth Movement Rates

Orthodontic treatment frequently requires moving some or all teeth over significant distances. Tooth movement is a physiologically rate-limited process where forces applied to teeth are transmitted through the periodontal ligament into alveolar bone causing it to either resorb or grow. ${ }^{12}$ Excess force can lead to hyalinization, which is a counter productive formation of necrotic bone that must be resorbed through a slower process resulting in slower tooth movements. ${ }^{13}$ However, Ren et al found in a 
systematic review and subsequent mathematical model that a wide range of clinically applicable forces $(135-471 \mathrm{~g})$ allowed human teeth to move approximately $1.1 \mathrm{~mm}$ per month, though variation can occur within and between individuals of a particular study even with identical mechanics. ${ }^{11,14}$ Numerous studies have confirmed teeth move about 1 $\mathrm{mm}$ per month and, consequently, closure of a typical $7 \mathrm{~mm}$ premolar extraction site requires approximately 7 months. ${ }^{15-19}$ In order to better understand the relationship between tooth movement rates and treatment mechanics, researchers have studied humans as well as other species in order to compare differing orthodontic force levels, intermittent versus continuous forces, and even bracket types.

Human Studies

Human studies have shown that continuous forces generally produce faster space closure rates than intermittent forces. Up to about $140 \mathrm{~g}$, increasing continuous forces result in increased tooth movement rates. ${ }^{15}$ Above about $140 \mathrm{~g}$ of continuous force, tooth movement rates do not significantly increase. Many studies show lighter, continuous forces move teeth faster than heavier, discontinuous forces. ${ }^{16,19,20}$ In addition, human research also showed twin brackets allow for faster tooth movement than self-ligating brackets. ${ }^{21}$

In order to evaluate the effect of applied force on tooth movement rates, Boester and Johnston ${ }^{15}$ performed a split-mouth, canine retraction study with spring forces approximating 55, 140, 225 and $310 \mathrm{~g}$. The springs were reactivated weekly over the 10 week study. While the $55 \mathrm{~g}$ group showed significantly slower rates of tooth movement, 
the other groups closed space at the same rate. The authors suggested that the force range of 140 to $310 \mathrm{~g}$ achieves a rate-limiting, maximal rate of bone resorption.

In a split-mouth study comparing lower force magnitudes, Iwasaki et al ${ }^{18}$ closed upper first premolar extractions spaces with continuous forces of $18 \mathrm{~g}$ and $60 \mathrm{~g}$ applied by NiTi closed coil springs. The author placed Nance appliances and colligated the first molars and second premolars to isolate tooth movement to the canine. The results showed $1.27 \mathrm{~mm}$ of tooth movement per month for the $60 \mathrm{~g}$ group and $0.87 \mathrm{~mm}$ per month for the $18 \mathrm{~g}$ group, demonstrating significant differences in the overall tooth movement rates. The major difference in tooth velocities occurred during the first three months. After this initial period, there was no significant difference.

Samuels et $\mathrm{al}^{16}$ compared extraction space closure performed with $150 \mathrm{~g}$ light continuous force, applied with NiTi closing coils, to a heavier intermittent force applied with 400 to $450 \mathrm{~g}$ elastomeric ligation. The continuous force closed space at $0.26 \mathrm{~mm}$ per week while the intermittent force closed space at a slower $0.19 \mathrm{~mm}$ per week. In a later study, Samuels et $\mathrm{al}^{17}$ demonstrated that $100 \mathrm{~g}$ and $200 \mathrm{~g}$ of continuous force closed space at $0.16 \mathrm{~mm}$ and $0.24 \mathrm{~mm}$ per week, respectively. Based on the results of these two studies, the $100 \mathrm{~g}$ NiTi continuous force and the 400 to $450 \mathrm{~g}$ intermittent force produced significantly lower rates of tooth movement than the 150 and $200 \mathrm{~g}$ NiTi of continuous force, which were not significantly different from each other.

The effects of intermittent versus continuous force application was studied by Nightingale and Jones, ${ }^{19}$ who compared canine retraction in a split mouth study. One side had continuous forces (209 g) applied with NiTi coil springs and the other side had 
intermittent forces (300 g) applied with elastomeric chains. The continuous force mechanics closed space at $0.26 \mathrm{~mm}$ per week and the intermittent force closed space at $0.21 \mathrm{~mm}$ per week. There was no statistical difference between the lighter continuous force and heavier intermittent force space closure.

Intermittent versus continuous space closure was also compared by Daskalogiannakis and McLachlan. ${ }^{20}$ They compared space closure performed on one side with a $70 \mathrm{~g}$ vertical retraction loop activated every six weeks against space closure with continuous forces on the opposite side applied using the same loop and $60 \mathrm{~g}$ rare earth magnets. The intermittent force closed space at $0.63 \mathrm{~mm}$ per month while the continuous force closed space significantly faster, at $1.22 \mathrm{~mm}$ per month.

Tooth movement with sliding mechanics can be affected by binding and friction between wires and brackets. Burrow ${ }^{21}$ performed a split-mouth study comparing selfligating (SmartClip ${ }^{\mathrm{TM}}$ and Damon3 $\left.{ }^{\mathrm{TM}}\right)$ and twin (3M Victory Series ${ }^{\mathrm{TM}}$ ) brackets to determine the relative roles of binding and friction. The canine being retracted was bonded with the bracket being studied, while the remaining teeth were bonded with Victory Series ${ }^{\mathrm{TM}}$ brackets. $150 \mathrm{~g}$ NiTi closed coil springs closed space on 018 stainless archwire. After four weeks, the canine with the twin bracket had moved $1.17 \mathrm{~mm}$, while the self-ligating brackets moved the canine $1.10 \mathrm{~mm}$ (SmartClip $\left.{ }^{\mathrm{TM}}\right)$ and $0.9 \mathrm{~mm}$ $\left(\right.$ Damon $\left.3^{\mathrm{TM}}\right)$. The authors explained that the narrower width of the self-ligating brackets may lead to increased binding, which may explain the significantly faster rates of tooth movement seen with the twin bracket. 
Dog Studies

Because the dog model exhibits similar alveolar bone characteristics as humans, research with this animal has contributed greatly to the understanding of tooth movement in humans. ${ }^{910}$ Dog studies have demonstrated that teeth move in four phases, including initial, arrest, acceleration, and linear. 50 to $200 \mathrm{~g}$ intermittent forces produced no significant differences between forces in these phases. Identical forces applied with continuous mechanics produce faster space closure than intermittent mechanics during the linear phase. Miniscrew anchorage also produced no difference in tooth movement at different force levels. ${ }^{22}$

While studying rates of second mandibular premolar distalization into third premolar extraction space of dog, Pilon et $\mathrm{al}^{23}$ defined the following four tooth movement phases: initial tooth movement phase, arrest of tooth movement phase, acceleration of tooth movement phase, and constant linear tooth movement phase. While the split-mouth study using 50,100, and $200 \mathrm{~g}$ pre-stretched elastic modules demonstrated a maximum of $2.5 \mathrm{~mm}$ per month, no significant difference occurred in movement rates or durations of the described phases. While the authors observed differences in tooth movement rates from dog to dog, the right and left sides of each dog were highly correlated.

While using miniscrew implants mesial to the fourth premolar, Owens et $\mathrm{al}^{22}$ evaluated retraction of mandibular second premolars into third premolar extraction spaces. Retraction forces of 25 and $50 \mathrm{~g}$, applied with NiTi coil springs to the miniscrew 
implants, resulted in no significant difference in tooth movements. Both sides showed a mean rate of $0.25 \mathrm{~mm}$ of movement per week.

Van Leeuwen et al24 evaluated the difference between light continuous and light intermittent forces in beagles. The mandibular second premolars were distalized into extracted third premolar spaces using NiTi springs producing 10.2 and $25.5 \mathrm{~g}$. The springs were either left in continuously or for 16 hours per day for the duration of the 120 day experiment. The authors also found that tooth movements exhibited four phases, namely initiation, arrest, acceleration, and linear. During the linear phase, the continuous force groups of $25.5 \mathrm{~g}$ and $10.2 \mathrm{~g}$ demonstrated space closures of $0.37 \mathrm{~mm}$ and $0.32 \mathrm{~mm}$ per week, respectively. For the same respective force levels, the discontinuous mechanics closed space at 0.25 and $0.21 \mathrm{~mm}$ per week during the linear phase. These results indicate equivalent continuous forces closed space faster during the linear phase.

Human and Dog Systematic Review

Ren et a ${ }^{14}$ performed a systematic review of orthodontic tooth movement in animals and humans. They sought to compare the rates of tooth movement and forces used in the various studies. The authors found that, despite consistent mechanics and forces, large differences in tooth movement can occur between subjects and even within individuals. Moreover, even with significantly different forces, tooth movement can be nearly identical between and within individuals. Ren and colleagues noted that these seemingly contradictory situations are possibly the result of individual variation in 
anatomy and cellular response to tooth movement. Differences could also be due to variation in local factors such as cytokines and growth factors.

In a follow up paper, Ren et $\mathrm{al}^{11}$ performed a systematic review to develop the mathematical relationship between tooth movement and force in both beagle dogs and humans. Their dog model predicts second mandibular premolar movement of $0.27 \mathrm{~mm}$ per week with an optimum force of $253 \mathrm{~g}$. The exact force value was not critical; the $95 \%$ confidence interval ranged from 106 to $463 \mathrm{~g}$. Their human model predicted that canines retract $0.29 \mathrm{~mm}$ per week under $277 \mathrm{~g}$ of force, with a $95 \%$ confidence interval of 135 to $471 \mathrm{~g}$. Ren et al concluded that human tooth and dog tooth movement rates are not significantly different and that they can be achieved over a wide range of forces, which also are not significantly different.

Tooth Movement Hypotheses

Numerous attempts have been made to explain the biology of tooth movement. The major hypotheses that have been proposed are mechanostransduction, piezoelectric, and pressure-tension.

As in many crystalline materials, applying mechanical pressure can result in a piezoelectric effect with an electric charge developing on the surface of bone. ${ }^{25,26}$ Bassett and Becker $^{27}$ indicated that stress-induced electrical potentials can lead to bone formation. It has been shown that as teeth move, positive ions briefly collect on the pressure side while negative ions move to the tension side. Upon force unloading, the ion polarity reverses. ${ }^{25}$ While studying bone remodeling, Davidovitch et al $^{26}$ showed that teeth move faster in the presence of an electric current than when there is no current. 
While possibly related, many researchers believe there is more to bone remodeling than changing ionic charges on the bone surface. The mechanotransduction hypothesis suggests orthodontic forces cause osteocytes within the bone to create an electrical or biochemical signal. ${ }^{28}$ Bone cells possess stretch-activated ionic channels which allow the passage of various ions including calcium. ${ }^{29}$ In addition, macromolecule connections exist between extracellular collagen to the transmembrane protein integrin. Mechanical excitations of this molecule are in turn transmitted to the nuclear membrane via the plasma protein actin and this causes osteocytic genomic activation. These bone remodeling signals are relayed between osteocytes via a cellular network of canaliculli and gap junctions called the ossesous cellular network. ${ }^{29,30}$

The pressure-tension hypothesis is based on the idea that the periodontal ligament (PDL) is affected by tooth movement. ${ }^{31,32,33}$ Specifically, the PDL compresses and blood flow is restricted on the side to which the tooth is moving. The PDL stretches and blood flow improves on the side the tooth is moving away from. Moreover, bone deposition occurs on the tension side and resorption is seen on the compression side. However, the amount of pressure dictates the type of resorption observed. Under light force, frontal resorption is characterized by osteoclasts removing bone immediately adjacent to the compressed PDL. Under heavy force, PDL blood flow is restricted and an acellular "hyalinized" necrotic zone occurs. In a process known as undermining resorption, this zone is resorbed by osteoclasts invading from the still viable medullary bone on the opposite side of the hyanilized tissue. 


\section{Effect of Bone Remodeling Rates and Density on Tooth Movement}

Bone turnover is clearly associated with orthodontic tooth movements. King et $\mathrm{al}^{34}$ evaluated molar movements in rats and found bone resorption on the pressure side and bone formation on the tension side. Tooth movement rates were proportional to the rates of bone turnover.

Verna et $\mathrm{al}^{35}$ separated Winstar rats into three groups, a control group, a high bone turnover group, and a low bone turnover group. Pharmacological induced thyroid changes were used to modify bone turnover in the "high" and "low" groups for four weeks prior to orthodontic tooth movement. The animal's molars were then mesialized using constant and equivalent forces for three weeks. The results showed faster movement with the high turnover group and slower tooth movement in the low turnover group when each was compared to the normal control. This confirmed the proportional relationship between bone turnover and tooth movement.

As one might expect, bone density also affects tooth movement. Goldie et al demonstrated this with 35 adult female rats were divided into a control group and a calcium deficient, lactating group. ${ }^{36}$ Orthodontic mesialization of the maxillary molars demonstrated faster movement in the calcium deficient group with less dense bone. The authors concluded that faster tooth movement was correlated with less dense bone.

In a similar study related to bone density, Ashcraft et al ${ }^{37}$ used cortisone acetate to cause osteoporosis in an experimental group of New Zealand white rabbits, which they compared to an untreated control group. The rabbits' maxillary molars were 
mesialized orthodontically. Teeth moved three to four times faster in rabbits with osteoporosis, again demonstrating faster tooth movement with lower bone density. Accelerating the Biology of Tooth Movement

Accelerated orthodontic tooth movement rates make it possible to reduce overall treatment times. Because increased bone turnover and decreased bone density produce faster orthodontic tooth movement, research has focused on ways to induce these conditions in bone.

Regional Acceleratory Phenomenon

Tooth movements can be accelerated by the regional acceleratory phenomenon (RAP), which increases bone remodeling rates and decreases bone density. ${ }^{38-40}$ The RAP is a complex reaction of tissue to noxious stimuli, which could include a crushing injury, a fracture, or an operation. The tissue response includes increased bone turnover and remodeling, increased cellular metabolism, growth of hard and soft tissue, and decreased regional bone density. The RAP has also been correlated to increased tooth movement, especially when the damage is extensive, such as with full flap elevation and corticotomies between tooth roots. ${ }^{41}$ Tooth movements have been shown to increase by two to five times. ${ }^{42-44}$ These effects are present for approximately 1-2 months in dogs and 2-3 months in humans. ${ }^{1}$

The RAP effect is proportional to the amount of insult. McBride et $\mathrm{al}^{45}$ demonstrated that more extensive bone injury results in greater decreases in bone density. Cohen et $\mathrm{al}^{12}$ also showed that more extensive injury increases tooth movement rates during premolar protraction into extraction sites. Researchers continue to 
investigate different means by which to induce the RAP, while still reaping the benefits of faster tooth movements. More recent research focuses on doing so with minimal tissue trauma and risk to the patient.

Corticotomies

Surgical corticotomy is a procedure that raises a full-thickness mucoperiosteal flap and cuts the cortex of alveolar bone around the tooth to be moved. Wilcko et al ${ }^{41}$ were the first to associate corticotomies and accelerated tooth movement with the RAP. In a split mouth study in beagle dogs conducted after allowing extraction sites to heal for 4 weeks, Cho et $\mathrm{al}^{42}$ found that corticotomies plus orthodontic force moved teeth two times faster in the mandible and four times faster in the maxilla versus controls without corticotomies. Furthermore, the authors noted that maximum tooth movement occurred at two weeks post-corticotomy. After allowing 16 weeks for extractions sites to heal, Iino et $\mathrm{al}^{43}$ also found faster tooth movement with corticotomies in dogs. Tooth movements were twice as fast during the first week and five times as fast during the second week. The overall result at the end of four weeks was twice the tooth movement. Sanjideh et $\mathrm{al}^{44}$ found that corticotomies performed the same day as extractions produced twice the tooth movement. They also found that a second corticotomy performed 4 weeks later produces statistically significant differences in total tooth movement, but the difference was not clinically significant and therefore a second corticotomy procedure is not warranted.

Corticotomies induce RAP in a localized fashion, without cross-over to the other side of the arch or beyond one tooth away from the injury. A rat study showed that 
selective alveolar decortication induced increased turnover of alveolar spongiosa that is localized to the area immediately adjacent to the decortication injury. ${ }^{46}$ Flapless Corticotomies

Due to the inherent risks - potential loss of alveolar bone height ${ }^{47}$ and possible dehiscence in areas of thin alveolar bone - and expense of a Wilcko style corticotomy surgery, researchers have sought alternate methods of achieving the RAP effect through less invasive means of injuring the bone, many of which do not involve raising a flap. Flapless approaches have induced bone injuries using a bone awl, ${ }^{48}$ a reinforced scalpel, ${ }^{49}$ a piezo knife, ${ }^{50-54}$ and a piezo endodontic tip. ${ }^{55}$ More recently, microosteoperforations (MOPs) have been created with a small bur in rats ${ }^{56,57}$ and with the PROPEL device in humans. ${ }^{58}$ Their aim was to produce the RAP and accelerate tooth movement, but with less tissue trauma and costs.

Microfracture Surgery

One method of inducing bone damage with less surgical intervention is with the use of an awl and mallet. The aim is to induce microfracture in the cortical bone. Swapp et $\mathrm{al}^{48}$ conducted a dog-study wherein multiple $(n=60)$ microfracture injuries were induced in the buccal and lingual cortical plates around the mandibular tooth to be moved. After 4 weeks of extraction site healing, a grid of microfractures was created over the area of the tooth roots and extended 5 to $6 \mathrm{~mm}$ into the extraction space. Target teeth were then moved with orthodontic force, but no difference was found in the rate of tooth movement between the experimental and control sides, even though microcomputed tomography $(\mu \mathrm{CT})$ results showed significant decreases in cortical bone 
volume fraction and cortical bone density on the experimental side. Histomorphometric images demonstrated cortical bone remodeling occurred on the experimental side whereas the control side showed almost no remodeling. Importantly though, the medullary bone exhibited no differences in bone volume or density between the two sides.

\section{Corticision}

In another type of supplemental dentoalveolar surgery, a reinforced scalpel is used to separate the interproximal cortices transmucosally without reflecting a flap. Kim et $\mathrm{al}^{49}$ investigated the biologic effects of corticision on alveolar remodeling during orthodontic tooth movement in cats. The animals were divided into three groups as follows: an orthodontic-only group (control), an orthodontic plus corticision group, and an orthodontic plus corticision and periodic mobilization group. While the cut depth was not specified, $0.4 \mathrm{~mm}$ wide corticisions penetrated through the gingiva, cortex, and into the medullary bone surrounding the canine. Results after 1,2,3 and 4 weeks of a 100-g orthodontic force showed that the orthodontic plus corticision group had 3.5 times more new bone apposition area than the orthodontic only group. Also, the orthodontic plus corticision group showed extensive direct resorption of bundle bone with less hyalinization and more rapid removal of hyalinized tissue. Notably, the majority of the effect lasted only about 4 weeks, which may not be long enough for typical extraction space closure.

In a later study, Kim et $\mathrm{al}^{59}$ again studied orthodontic movement differences in response to adjunct therapy. This study was conducted using dogs and evaluated the 
effects of both corticision and Low-Level Laser Therapy (LLLT) on tooth movement rates. Their animals were grouped as follows: an orthodontics only group, an orthodontics plus corticision group, an orthodontics plus LLLT group, and an orthodontics plus corticision and LLLT group. After 4 weeks of extraction site healing, corticision was performed on the mesiobuccal, distobuccal, mesiopalatal, and distopalatal sides of the maxillary second premolar. The blade used in surgery penetrated $10 \mathrm{~mm}$ through the gingiva and into the cortical and medullary bone. Maxillary second premolars were then protracted with NiTi springs ( $150 \mathrm{~g})$ for 8 weeks. Teeth in the orthodontics plus corticision group moved 3.8 times more than the teeth in the orthodontics only group. However, it is important to note that their injuries penetrated much further than traditional corticotomy. Also, the major effect lasted only about 4 weeks.

Piezocision

In a case report, Dibart et $\mathrm{al}^{50}$ introduced a novel technique aimed at inducing the RAP and enhancing tooth movement. The minimally invasive procedure combined microincisions with selective tunneling performed with piezoelectric incisions. Though tooth movements were not measured, the authors claimed that this novel approach allows shorter orthodontic treatment, minimal discomfort, and a stronger and thicker periodontium because of the added grafting.

Ruso et a $1^{54}$ performed a split-mouth, flapless piezocision corticotomy procedure on dogs. $5 \mathrm{~mm}$ deep by $15 \mathrm{~mm}$ long cuts were made mesial and distal to and within the furcation of the maxillary second premolar. The control side received a sham surgery of 
incision and suturing only, with no flap or bone injury. An appliance loaded the second premolar with $173 \mathrm{~g}$ of force in a buccal direction for 9 weeks followed by 2 weeks of consolidation. The experimental teeth moved $35 \%$ faster than controls, far less than twice the tooth movement seen in other corticotomy surgerys. Ruso and coworkers speculated the lack of effect was due to the procedure not including a full thickness flap. Piezopuncture

Kim et al ${ }^{55}$ performed another study that used a somewhat different approach for accelerating tooth movement with minimal surgical invasion. This approach, currently applied in preprosthetic surgery, alveolar crest expansion, and sinus grafting, utilized an ultrasonic piezotome tip to induce cortex damage to a depth of $3 \mathrm{~mm}$ in sixteen positions around the target tooth, including both lingual and buccal surfaces. While the tip diameter was not specified, the instrument was described as having "a sharp curved tip." The proposed advantage of this technique over corticision is that piezopuncture is better tolerated by patients, with damage being induced through direct, steady pressure of the tip into the cortex for 5 seconds versus the corticision procedure, which requires "malleting" the blade into the cortical bone. The six week study was conducted with 10 beagles divided into an orthodontics only group (control) and an orthodontics plus piezopuncture group. Tooth movements were significantly greater in the piezopuncture group. Specifically, the maxillary teeth moved 3.3 times more in the experimental group than the control group, and the mandibular teeth moved 2.5 times more in the experimental group than in the control group. The effects were limited in duration. As 
Kim et al also reported for corticision, they also suggested that piezopuncture could be repeated as needed since it is a more patient-tolerable procedure.

Micro-osteoperforations

In another attempt to minimize patient trauma while still producing the RAP effect, researchers developed a technique called micro-osteoperforation (MOP). This technique was first studied in rats using a small bur to create cortical injuries. This was followed by a human study where MOPs were created using a device with a small screw tip that punctures through the soft tissue and into cortical bone.

Teixeira et $a^{56}$ conducted research on rat maxillae, in which the first molars were protracted with a $51 \mathrm{~g}$ load. They evaluated the differences between orthodontic forces alone, orthodontic force plus a full thickness flap, and orthodontic force plus a flap and MOPs. The MOPs were created by drilling a $0.25 \mathrm{~mm}$ deep hole, with a $0.25 \mathrm{~mm}$ bur, after a flap was raised. Three MOPs were made $5 \mathrm{~mm}$ mesial to the first molar on one side of the mouth only. The other side served as the control with no treatment. The study measured bone density, tooth movement, osteoclast count, and cytokine count. All four parameters were higher for the orthodontic force plus flap and micro-osteoperforations group than for the other groups. The authors concluded that MOPs add a beneficial RAP effect above orthodontics alone or orthodontics plus a flap. Tooth movement results for the orthodontics alone group and orthodontics plus a flap group were not statistically different. This contradicts other findings showing that increased trauma due to raising a flap increases the RAP affect, and produces faster tooth movement. ${ }^{60}$ 
Baloul et al also conducted a rat study with bur MOPs. ${ }^{57}$ Ten MOPs similar to those placed by Teixeira were placed after raising a flap on the experimental side only. The control side had no flap and no MOPs. After applying $25 \mathrm{~g}$ of force bilaterally, Baloul et al saw no significant difference in tooth movement despite raising a flap, which is known to cause accelerated tooth movements, ${ }^{60,61}$ and placing more MOPs than did Teixeira et al.

A study by Safavi et al ${ }^{62}$ investigated flapless corticotomies induced with a surgical bur, which induces an injury like a micro-osteoperforation. Five adult German Shepherd dogs served as their own controls in this split-mouth study. The corticotomies were produced with a surgical bur drilled $2 \mathrm{~mm}$ deep through the buccal cortex mesial, buccal and distal to the second premolar. There was no healing time between extractions and corticotomies. While the publication does not specify the bur diameter, the injuries were reported as "small holes ... using a fine surgical fissure bur." The second premolars were immediately loaded for mesialization into first premolar extraction spaces. A NiTi spring applied 150 grams for 3 months. Corticotomies were performed immediately after extraction, at 1 month, and at 2 months. The study lasted 3 months. Results showed that the experimental premolars moved 1.6 times faster than the control premolar over the first month. However, the second and third month showed no statistically significant differences in tooth movement velocities compared to the control. Safavi and coauthors noted that the reduction in tooth movement rates during the second and third months resulted from the distal root encountering the mature lamellar bone, which was produced on the distal aspect of the mesial root as the tooth moved mesially. Safavi et al explained 
that the more mature lamellar bone resulted from biologic materials being recruited following decortication and that this caused increased bone turnover and accelerated bone maturation.

The PROPEL device was developed from the MOP research. It uses a surgical steel miniscrew to produce $1.5 \mathrm{~mm}$ diameter holes at variable depths through the gingiva and cortical plate adjacent to teeth to be orthodontically moved. ${ }^{58}$ Alikhani et a ${ }^{58}$ conducted a study in which 20 Class II Div 1 adult patients requiring bilateral canine retraction into premolar extraction spaces were divided into two groups, an orthodontics plus MOP group and an orthodontics-only control group. After allowing the extraction site to heal for 6 months, the experimental side received three $1.5 \mathrm{~mm}$ diameter by 2 to 3 $\mathrm{mm}$ deep micro-osteoperforations with the PROPEL device on one side of the maxilla. The three MOPs were placed in a vertical line between the canine and second premolar. The contralateral side of the same patient and both sides of a separate patient control group received no MOPs. Canine retraction occurred via a $100 \mathrm{~g}$ NiTi coil spring connected to a miniscrew placed mesial to the first molar. At the end of four weeks, there was approximately $1.3 \mathrm{~mm}$ of tooth movement in the orthodontic-plus-MOP group measured. Approximately $0.6 \mathrm{~mm}$ of movement occurred on the orthodontic-only side, indicating a 2.3 times increase in the tooth movement rate following MOP treatment. As shown previously, there is abundant orthodontic literature demonstrating that traditional orthodontics-only tooth movements occur at a rate of about $1 \mathrm{~mm}$ per month. ${ }^{11}$ While MOP based orthodontics increased tooth movements over non-MOP techniques within this study, the PROPEL MOP-based results of $1.3 \mathrm{~mm}$ per month 
cannot be assumed to accelerate tooth movements beyond already achievable orthodontic-only techniques. Also, because this study was conducted on human subjects, histology, bone density, and bone turnover comparisons could not be made between MOP-assisted orthodontics and orthodontics-only affects on bone.

Summary

The literature consistently demonstrates that approximately $1 \mathrm{~mm}$ per month of tooth movement can be reasonably expected with non-accelerated, orthodontic-only treatment modalities. Since the 1980s, the RAP effect has been extensively studied and clearly associated with accelerated tooth movement. Moreover, it has been shown that the RAP effect is proportional to the extent of injury. ${ }^{12,45,63}$ Researchers have attempted to induce the RAP with various approaches.

On the more extreme end, full thickness flaps with corticotomies are well established as inducing the RAP and accelerating tooth movement. Even raising a flap alone has been shown to increase tooth movements..$^{60,61}$ On the less extreme end, Alikahani et al ${ }^{58}$ concluded from a human study that bone injury resulting from three micro-osteoperforations of 2-3 mm depth also induces sufficient damage to induce the RAP and more than double tooth movement rates. Moreover, Kim et a ${ }^{55}$ showed piezopuncture, a minimally invasive technique of inducing sixteen $3 \mathrm{~mm}$ deep injuries with an endodontic piezo tip also accelerate tooth movement. Both Alikahani's MOP results and Kim's piezopuncture results are surprising considering the fact that Swapp's dog study induced sixty 2-3 mm deep cortical defects using a bone awl without marked 
differences in medullary bone density or volume and also without significant differences in tooth movement rates. ${ }^{48}$

In light of these conflicting results and the fact that no histologic studies to date have evaluated the RAP and the extent to which bone changes occur in response to MOPs, this split-mouth dog study proposes to evaluate MOP effects via linear measurements of tooth movement, $\mu \mathrm{CT}$ evaluation of bone density and bone volume fraction, fluorescent label evaluation of bone mineralization in the area of MOP, and histological differences in the beagle maxilla. 


\section{CHAPTER II}

\section{PURPOSE AND SIGNIFICANCE}

Depending on case complexity, the duration of most comprehensive orthodontic treatments range from one to three years, with non-extraction cases requiring 21-27 months and extraction cases requiring 25-35 months. ${ }^{1}$ Treatment times depend on the orthodontic mechanics employed, patient cooperation, and, particularly in extraction cases, the distance that teeth need to be moved. ${ }^{2-4}$ Longer treatment times increase the risk of root resorption, ${ }^{5,6}$ decalcification, ${ }^{7}$ and periodontal problems. ${ }^{8}$ Orthodontic research seeks to reduce treatment time and the associated risks, while still providing uncompromised treatment results.

Orthodontic tooth movements are physiologically rate-limited by how fast alveolar bone can model and remodel around the moving tooth. ${ }^{12}$ The orthodontic literature shows that tooth movements occur at approximately $1 \mathrm{~mm}$ per month. ${ }^{11,15-19}$ Tooth movements can be increased by inducing the regional acceleratory phenomenon (RAP) with corticotomy procedures. ${ }^{42-44}$ The RAP is a response to the injury caused by these procedures; it accelerates existing biological processes, decreases bone density, and increases bone turnover. ${ }^{38}$

Corticotomy procedures designed to stimulate the RAP, as first popularized by the Wilcko brothers, included raising a full-thickness flap and cutting through the cortical bone around teeth to be moved faster. ${ }^{41}$ Dog studies have demonstrated that teeth move approximately twice as fast when a flap and alveolar decortication are 
performed, though the accelerated movements appear to be limited to the first $2-4$ weeks. ${ }^{43,44}$ Corticotomy procedures insult the bone through the disruption of blood flow caused by raising a full thickness flap and by direct mechanical injury to the bone. The procedures are not without risk, including inherent surgical risks including infection, nerve damage, and anesthesia complications, the potential loss of alveolar bone height, ${ }^{47}$ and possible dehiscences where thin alveolar bone exists. ${ }^{61}$ In order to reduce these risks, several studies have evaluated flapless corticotomies with less insult to the bone, though results have been conflicting.

In a rat model, Teixeira et al demonstrated twice as much molar movements with flap surgeries and three micro-osteoperforations (MOPs) than when raising a flap alone; they concluded that MOPs were sufficient to induce the RAP and faster tooth movements. ${ }^{56}$ Baloul et al performed a similar rat study that flapped only the experimental side and placed ten MOPs near the targeted teeth, but found no significant differences in tooth movements. Similarly, flapless perforations of cortical bone in dogs had no significant long-term effects on tooth movements. ${ }^{48,62}$ Swapp et al showed that there were no side differences in tooth movement because the bone surrounding the teeth had not been affected by the flapless cortical perforations. ${ }^{48}$ In a clinical trial, Alikhani et al used the PROPEL device to place MOPs into upper premolar extraction sites in patients requiring canine retraction. ${ }^{58}$ They reported twice as much experimental than control tooth movement over the 28 days of their study. 
In light of these conflicting results, the purpose of the present study was to evaluate the effects of MOPs - produced with PROPEL - on tooth movements and bone using a canine model, which more closely resembles human bone and tooth structures. 


\section{CHAPTER III}

\section{MATERIALS AND METHODS}

Seven skeletally mature male beagle dogs, approximately 24 months of age and weighing 21- 25 pounds, were used in this experiment. All of the animals had fully erupted dentitions and were healthy. Dogs were selected because the canine has been well established as one of the best animal models for investigating tooth movements and bony adaptation. ${ }^{9,10}$ Housing, care, and experimental protocols were approved by the Institutional Animal Care and Use Committee at Texas A\&M University, Baylor College of Dentistry (IACUC 2014-0267-BCD). During the course of the experiment, the dogs were fed a soft diet to minimize damage to the orthodontic appliances. Extractions and Initial Records

Following a 10-day quarantine, initial records were taken. The animals were fasted for 12-hours and then sedated with an intramuscular injection of ketamine (8-24 $\mathrm{mg} / \mathrm{kg} \mathrm{IM})$ mixed with xylazine $(0.22 \mathrm{mg} / \mathrm{kg} \mathrm{IM})$. Dental prophylaxis using a Cavitron Select ultrasonic scaler (Denstply, York, PA), irrigated with $0.12 \%$ chlorhexidine gluconate was performed. Photos were taken, as well as right and left periapical radiographs using a Planmeca Intra X-Ray unit (Planmeca USA, Roselle, IL). The radiographs were taken using a custom designed cephalostat (Figure 1A), which was used to standardize the X-Ray tube position, the dog's head position, and the size 4 film position. A representative sample of radiographs for one dog is shown in Figure 1B-F. For each dog, an occlusal plate was fabricated with custom impressed Triad 
(Dentsply, York, PA) pads. For each radiograph, the occlusal plate was secured to the dog's snout and inserted into a slot on the cephalostat base. A radiographic phosphor plate was placed on a $17^{\circ}$ inclined plane support and the support was inserted between the cephalostat base and the dog's maxilla. The X-Ray tube was inserted into a holder at the top of an extension from the cephalostat base and radiographs were recorded.

Triad custom tray material (Dentsply, York, PA) was used to make maxillary impression trays, and alginate impressions of the maxilla were taken. The impressions were poured in die stone and the models were used for appliance fabrication. Local anesthetic (2\% lidocaine with 1:100,000 epinephrine) was administered at the extraction sites via regional infiltration. Both maxillary third premolars were sectioned, elevated, and extracted. The tissue was reapproximated with simple interrupted 4-0 Vicryl resorbable sutures. Immediately after surgery, the dogs were given a single dose of ketoprofen $(1 \mathrm{mg} / \mathrm{kg} \mathrm{IM})$. For the next week, they were also given post-operative analgesic (nalbuphine $2 \mathrm{mg} / \mathrm{kg} \mathrm{IM}$ ) and antibiotics (clindamycin $11 \mathrm{mg} / \mathrm{kg}$ IM) twice daily.

Appliance Design

Appliances were fabricated utilizing the stone models poured from the alginate impressions taken during the initial records (Figure 2). Orthodontic band material (Dentaurum, Ispringen, Germany) was custom pinched and welded to fit the maxillary canines, second premolars, and fourth premolars. The interior aspect of each band was micro-abraded and the bands were perforated with $1 \mathrm{~mm}$ holes to maximize retention onto the tooth. 
Headgear tubes of 0.051 " diameter (3M Unitek, Monrovia, CA) were soldered to the orthodontic bands on the second and fourth premolars. Stainless steel orthodontic wire of 0.051 " diameter was soldered to the canine bands and inserted through the headgear tubes on the bands of the fourth premolars. These served as "guard wires" to protect the appliance. An additional 0.051 " diameter wire was soldered to the fourth premolar bands. This served as a "guide wire" along which the second premolar was translated. Stainless steel was used for the tube and wires in order to minimize friction. Also, tipping and binding were minimized since the 0.051 " wire diameter closely fit the nominal 0.051 " headgear tube.

Spring attachment loops made of 0.020 " stainless steel wires were soldered to the distal aspect of the second premolar bands and to the mesial aspect of the fourth premolar bands. Springs were attached bilaterally between the second and fourth premolars at the time of appliance delivery. MOP Placement, Appliance Delivery and Initial Records 28 days after extraction of the maxillary third premolars, the animals were prepared for appliance placement and MOP surgery. Following initial sedation with the ketamine and xylazine cocktail previously described, the dogs were intubated and administered $1-1.5 \%$ isoflurane in oxygen at a rate of $1 \mathrm{~L} / \mathrm{min}$. Vital signs were monitored throughout. Dental prophylaxis using an ultrasonic scaler, irrigated with $0.12 \%$ chlorhexidine gluconate, was performed.

The experimental surgical side was chosen using an electronically generated random number table. On the experimental side, 8 micro-osteoperforations (MOPs) were 
made using the PROPEL device (Propel Orthodontics, LLC, Milpitas, CA). The PROPEL miniscrew tip was $1.5 \mathrm{~mm}$ in diameter. The tip was inserted to the device's maximum allowable depth of $7 \mathrm{~mm}$, which included mucosa thickness. Two MOPs were placed within the furcation area of the maxillary second premolar, approximately $4 \mathrm{~mm}$ apart (Figure 3). Six additional MOPs were placed approximately $3 \mathrm{~mm}$ distal to the second premolar, configured in a rectangular pattern with approximately $4 \mathrm{~mm}$ spacing between MOPs. No MOPs were placed on the control side.

Bone markers [3 mm long titanium miniscrew implants] were placed for radiographic reference. A total of four markers were placed in the maxilla, two on each side. The heads of the screws were inserted to just below the tissue level and the gingival tissue was allowed to heal over the head. A $0.12 \%$ chlorhexidine gel was applied to the MOP and miniscrew sites using sterile cotton tip applicators.

Using a diamond tip bur, retention grooves were cut around the canines, second premolars, and fourth premolars. The teeth were mirco-etched and then etched with $37 \%$ phosphoric acid gel for $15 \mathrm{~s}$. After irrigating and drying the teeth, the appliance was cemented as a single unit on each side of the arch with light-cured RelyX Unicem 2 Automix (3M ESPE, Neuss, Germany) resin cement. Excess cement was removed to prevent gingival irritation. The appliances were activated by attaching $6 \mathrm{~mm}$ medium NiTi closed coil springs (Ormco, San Dimas, CA) from the soldered hook on the second premolars to the soldered hook on the fourth premolars using 0.008 " stainless steel ligature wire. The springs were activated to $200 \mathrm{~g}$. Force was verified throughout the experiment using a Correx force gauge (Haag-Streit, Bern, Switzerland). A small 
amount of Transbond XT (3M supplier info) was cured over the sharp ends of the ligature ties and over the ends of the guard wires to prevent irritation.

To standardize the intra-oral measurements, notches were cut into the cusp tips of the canine, second premolar, and fourth premolar. Digital calipers (RadioShack, Fort Worth, TX) were used to measure (to the nearest $0.01 \mathrm{~mm}$ ) the distance between the second premolar and fourth premolar. Three replicate caliper measurements were made at each measurement occasion and averaged. To aid in measuring tooth movements on radiographs, amalgam markers were placed into small ( $\sim 1 \mathrm{~mm}$ deep) preparations drilled into the enamel of the canine, second premolar, and fourth premolar. Dental amalgam was triturated and packed into the preparations. Post-operative periapical radiographs were taken using the described cephalostat. Intraoral photos were also taken. Measurements and Analysis

Intra-oral caliper measurements, photographs, and periapical radiographs were again taken at weeks $1,3,5$, and 7 . At each occasion, the NiTi spring was retied and calibrated using the Correx gauge to ensure that $200 \mathrm{~g}$ of force was being delivered. A single investigator $(\mathrm{CC})$ recorded all intra-oral measurements for consistency. The investigator was blinded regarding which side was control and experimental and, by week 1 , the MOP sites were fully healed so that the experimental and control sides could not be distinguished.

To evaluate the amount and location of subsequent bone modeling, calcein green $(10 \mathrm{mg} / \mathrm{kg}$ intravenously) was administered at week 3 . Alizarin red $(20 \mathrm{mg} / \mathrm{kg}$ intravenously) was administered at week 5 and calcein green was again administered at 
6.5 weeks.

After seven weeks of second premolar retraction (day 49), the animals were again sedated with the previously described ketamine and xylazine cocktail and final records were obtained, including periapical radiographs, caliper measurements, photographs, and impressions. The common carotid arteries were then both cannulated and the external jugular veins were severed. An intracardial injection of $2 \mathrm{cc}$ beuthanasia-D was given. After cessation of heart function was confirmed, approximately $1.5 \mathrm{~L}$ of saline followed by $1 \mathrm{~L}$ of $4 \%$ paraformaldehyde was flushed through the cannulas. The maxilla was then harvested and stored in $4 \%$ paraformaldehyde for 10 days and then $0.5 \%$ paraformaldehyde until samples were collected for histology and $\mu \mathrm{CT}$.

Radiographic Analysis of Movement

Periapical radiographs were imported into Viewbox 4.0 (DHAL Software, Kifissia, Greece). Using a custom protocol, all radiographs were analyzed to quantify the translation and tipping of the second premolar. A single, blinded investigator (CC) digitized the radiographs; also, MOPs were not visible on the radiographs so the experimental and control sides could not be distinguished.

The mesial crest of the fourth premolar, the distal crest of the canine, the mesial and distal root apices of the second premolar, and the furcation of the second premolar were digitized (Figure 4). A line connecting the alveolar crests of the canine and the fourth premolar was used as the alveolar crest reference line. Another line representing the long axis of the tooth was drawn from the second premolar root apex midpoint 
through its furcation. The angle formed between the long axis line of the second premolar and the alveolar crest reference line was used to assess tipping. Additionally, the midpoint of the furcal bone along the long axis of the second premolar was calculated and used as an approximate center of resistance of the tooth. This center of resistance was projected perpendicularly onto the alveolar crest reference line. The distance from this projected point to the mesial crest of the fourth premolar on the alveolar crest reference line was used to measure second premolar translation. $\mu \mathrm{CT}$ Assessment of Bone Density

After sacrifice, all specimens were sectioned to include the second premolar, its furcation, and the distal bone into which the second premolar was being moved (Figure 5). These segments fit in $27 \mathrm{~mm}$ wide $\mu \mathrm{CT}$ tubes. They were stabilized so that the buccal surface was perpendicular to the long axis of the specimen tubes, which were filled with $70 \%$ ethanol and sealed with parafilm (Pechiney Plastic Packaging Company, Chicago, IL). The entire distal MOP site and second premolar were scanned using the Scanco $\mu$ CT 35 scanner (ScanCo Medical, Basserdorf, Switzerland). The specimens were imaged at $30 \mu \mathrm{m}$ resolution, using $55 \mathrm{kVp}, 145 \mu \mathrm{A}$ and $800 \mathrm{~ms}$ integration time. Bone volume fraction and bone density were calculated with Analyze V12.0 software (AnalyzeDirect, Overland Park, KS).

The same volume of interest was defined for analysis on both the experimental and the control sides of the maxilla. It included the alveolar bone immediately distal to the second premolar (Figure 5). The volume was constructed as a $0.3 \mathrm{~mm} \times 0.3 \mathrm{~mm}$ square cross-section (occlusal view) extending down the length of the distal surface of 
the distal root at the mid-buccolingual position. The middle $80 \%$ of the distal root length was determined by locating the slice where the apex began and the slice where the alveolar bone crest began and removing the $10 \%$ of slices at each end. The bone volume to total volume ratio and bone density were both measured for the volume of interest. Histologic and Fluorescent Image Evaluation of Specimens

Five randomly selected specimens were cut to harvest the bone for hematoxylin and eosin $(\mathrm{H}+\mathrm{E})$ staining. The samples were sectioned through the distal root of the second premolar, so that one portion included the mesial half of the distal root, the furcation, and the mesial root. The remaining portion of the sectioned sample included the distal half of the second premolar root plus the bone containing the distal MOP field as seen in the radiograph in Figure 5A. The specimens were decalcified in ethylenediaminetetraacetic acid, dehydrated in graded alcohol, cleared with xylene, then infiltrated and embedded in paraffin. The specimens were cut along the sagittal plane to a thickness of 5 to $6 \mu \mathrm{m}$. Starting with the section closest to the buccal cortical surface, every 15 th to 20 th section was selected for a total of approximately 10 sections per tooth that were mounted. These sections were mounted to glass slides and stained with hematoxylin and eosin to evaluate the bone appearance and presence of MOPs. The section images were captured at 20x magnification and digitized using an Olympus VS120 Virtual Slide Scanner (Olympus Scientific Solutions Americas Corp., Waltham, Massachusetts).

Two undecalcified specimens were sectioned to include the second premolar roots and furcation and also the bone containing the distal MOP field. Alizarin red and 
calcein green staining images were captured at $5 \mathrm{x}$ magnification and digitized using an Eclipse 80i microscope (Nikon, Tokyo, Japan).

Statistical Analyses

All statistical analyses were performed by IBM SPSS ${ }^{\circledR}$ version 23 . Because the skewness and kurtosis statistics showed normal distribution, the data were summarized with means and standard deviations. Side differences were evaluated using paired ttests. 


\section{CHAPTER IV}

RESULTS

After surgery, healing proceeded normally without any signs of swelling or infection. During the course of the experiment, two dogs had spring detachment, a solder joint fail, or a bent wire (Table 1). All appliances were repaired the same day the issue was detected.

Table 1: Adverse events related to appliances

\begin{tabular}{|c|c|c|c|c|}
\hline Dog & Week & Description & Impact & Action \\
\hline 6 & 3 & $\begin{array}{c}\text { Experimental side } \\
\text { spring disengaged }\end{array}$ & $\begin{array}{c}\text { Up to 2 weeks } \\
\text { without spring force }\end{array}$ & $\begin{array}{c}\text { Repaired at Week 3 } \\
\text { Records }\end{array}$ \\
\hline 2 & 5 & $\begin{array}{c}\text { Control side guard } \\
\text { wire solder joint } \\
\text { failed. }\end{array}$ & $\begin{array}{c}\text { None since retraction } \\
\text { wire undamaged }\end{array}$ & $\begin{array}{c}\text { Repaired at Week 5 } \\
\text { Records }\end{array}$ \\
\hline 6 & 5 & $\begin{array}{c}\text { Control side guard } \\
\text { wire bent against P2 } \\
\text { bracket }\end{array}$ & $\begin{array}{c}\text { Potentially reduced } \\
\text { P2 movement }\end{array}$ & $\begin{array}{c}\text { Repaired at Week 5 } \\
\text { Records }\end{array}$ \\
\hline 6 & 6.5 & $\begin{array}{c}\text { Control side guard } \\
\text { wire bent against P2 } \\
\text { bracket }\end{array}$ & $\begin{array}{c}\text { Potentially reduced } \\
\text { P2 movement }\end{array}$ & $\begin{array}{c}\text { Repaired at Week 6.5 } \\
\text { Celcein Delivery }\end{array}$ \\
\hline
\end{tabular}

Tooth Movements

Intraoral caliper measurements showed that space closure between the second and fourth premolars was significant compared to the initial position for both sides. The crown moved $0.86 \pm 0.47 \mathrm{~mm}$ and $0.94 \pm 0.41 \mathrm{~mm}$ on the control and experimental 
sides, respectively (Figure 6). There was no significant group difference ( $p>0.05$ at each measurement occasion) for the intraoral measurements.

Radiographic measurements also showed that space closure between the second premolar and fourth premolar was significant compared to the initial position on both sides, with $0.79 \pm 0.50 \mathrm{~mm}$ of movement on the control side and $1.06 \pm 0.43 \mathrm{~mm}$ on the experimental side (Figure 7). The group difference between the control and experimental side movements was not statistically significant $(p>0.05)$ at any of the measurement occasions. The second premolars tipped a total of $0.73 \pm 3.14^{\circ}$ and $0.45 \pm 2.98^{\circ}$ on the control and experimental sides, respectively, with no statistically significant difference (Figure 8).

$\mu \mathrm{CT}$ and Histological Assessments

$\mu \mathrm{CT}$ analysis showed that the density of the alveolar bone adjacent to the second premolar was slightly higher on the control $\left(4639 \pm 339 \mathrm{mg} \mathrm{HA} / \mathrm{cm}^{3}\right)$ than the experimental $\left(4467 \pm 273 \mathrm{mg} \mathrm{HA} / \mathrm{cm}^{3}\right)$ side, but the difference was not statistically significant $(p=0.237$, Figure 9). Bone volume fraction of bone adjacent to the second premolar was lower on the experimental $(0.33 \pm 0.13)$ side than on the control $(0.37 \pm$ $0.18)$, but the difference was not significant $(\mathrm{p}=0.398$, Figure 10$)$.

The $\mathrm{H}+\mathrm{E}$ sections showed evidence of resorption, including Howships lacunae and osteoclasts resorbing mature alveolar bone on the compression side of the translating tooth (Figure $11 \& 12$ ). Also, the compression side of the tooth roots showed resorptive lacunae in some locations. On the tension side, osteoblasts and newly formed woven bone were observed, with a bone front cement line apparent at the intersection of new 
and old bone (Figure 13). Because the thickness of the bone front was nearly uniform thickness from the coronal to the apical aspect of the root surface, the parallel bone front supports primarily translation and only minimal tipping occurred during tooth movement.

The experimental alveolar bone appeared similar in appearance to control bone (Figures $11 \& 12$ ). Both had a mixture of woven and lamellar bone. New woven bone was being formed at the extraction site margins in both experimental and control samples.

MOPs in the furcation and in the distal MOP area were visible on the $\mathrm{H}+\mathrm{E}$ experimental sections. A mixture of woven and lamellar bone was seen within the MOP border (Figures 12B-C). At the MOP border, active remodeling was taking place as indicated by osteoblastic and osteoclastic activity (Figure 12B-C). This remodeling extended approximately $300 \mu \mathrm{m}$ from the MOP border.

Areas of empty lacunae (acellular bone) were noted around the perimeter of the MOPs (Figure 12B-C). As little as $20 \%$ and as much as $85 \%$ of the MOP perimeters were surrounded with acellular regions. The acellular region thickness generally extended 200 to $500 \mu \mathrm{m}$ from the MOP border. One MOP showed an acellular region extending approximately $800 \mu \mathrm{m}$ from the MOP border (Figure 12B). One acellular region extended to the resorbing tooth socket (Figure 12C). In the control samples, the bone adjacent to the resorbing bone front was cellular (lacunae contained osteocytes, Figure 11).

In some acellular regions of experimental bone, there were small clusters of 
lacunae with osteocytes in close proximity to Haversion canals (Figure 12C). Beyond the acellular region, the mature bone exhibited an appearance consistent with control bone. In the control bone, small regions of empty lacunae were noted, but generally the bone was cellular (Figures 11B-C).

The fluorescent images showed bone mineralization during the experiment (Figure 14). The green label indicated that bone was mineralized when calcein was administered at 3 weeks and then again 6.5 weeks into the experiment. The red label indicated bone that was mineralized when alizarin red was administered at 5 weeks. With the exception of the actual MOP sites, the experimental sections showed similar bone mineralization to the control side sections. This was true for the bone in the second premolar furcation and also for the alveolar bone immediately distal to the second premolar.

A magnified fluorescent image of a MOP hole (Figure 15) shows that bone mineralization was primarily contained within the original MOP border; the limited turnover within $1.0 \mathrm{~mm}$ of the MOP border may represent remodeling of microfractures. 


\section{CHAPTER V}

\section{DISCUSSION}

In this study, the overall increases in tooth movements produced with MOPs were small, indicating that the extent of the device's effect was limited. After seven weeks, the teeth on the experimental side had moved only $0.05-0.27 \mathrm{~mm}$ more than the teeth on the control side, differences that were neither statistically nor clinically significant. Previous studies evaluating the effects of MOPs on tooth movements are inconsistent. Using rats as their experimental models, Teixeira et $\mathrm{al}^{56}$ reported significant differences in tooth movements with three MOPs, while Baloul et $\mathrm{al}^{57}$ found no differences beyond 1 week with ten MOPs. The reason for the different outcomes is unclear, though there were variations in the study designs; Teixeira et al applied $51 \mathrm{~g}$ of force and flapped both the experimental MOP side and control side, whereas Baloul et al applied only $25 \mathrm{~g}$ of force and flapped only the MOP experimental side. Evaluating the effects of MOPs on tooth movements in dogs, Safavi et al, ${ }^{62}$ reported faster tooth movements during the first month, no differences during the second month and slower tooth movements during the third month. Swapp et $\mathrm{al}^{48}$ performed flapless perforations in dogs and found no effects on tooth movements or on the bone through which the teeth were being moved. In humans, Alikhani et $\mathrm{al}^{58}$ placed three MOPs without flaps and showed faster tooth movements on the experimental than control side during the first 28 days. The present study was the first to evaluate the biological effects of MOPs in a large animal model, which more closely resembles human bone and tooth structures. 
When MOPs are placed three or more millimeters away from the tooth being moved, they do not increase tooth movements because they have no major effect on either the amount or density of bone adjacent to the teeth being moved. The density and volume fraction of bone adjacent to the teeth being moved in the present study were $3.7 \%$ and $10.7 \%$ less than in controls, respectively. This is consistent with VanGemert, who reported density reductions of $3.8 \%$ at $3 \mathrm{~mm}$ from the MOP border. ${ }^{64}$ Swapp et al, who created flapless cortical injuries, also found no differences in bone density or bone volume in medullary bone, and also reported no differences in tooth movements. ${ }^{48}$ Owen et $\mathrm{al}^{60}$ reported reductions in density and bone volume similar to those in the present study and a 33\% increase in tooth movements, but they also raised a flap. Since the RAP effect is proportional to the amount of injury, ${ }^{12,45}$ and since MOPs might be expected to produce less of an insult than flaps, a lesser effect on bone adjacent to the teeth and lesser increases in tooth movements might be expected with MOPs. Importantly, the exact amount of change in bone volume or density required to alter tooth movements remains unknown and needs to be established in future studies.

Propel indicates MOPs should be placed within a $10 \mathrm{~mm}$ radius of the tooth to be moved and MOPs were placed approximately $3 \mathrm{~mm}$ from the teeth to ensure an effect. ${ }^{65}$ However, the principal visible effects of the MOP appear to be limited to approximately $1-1.5 \mathrm{~mm}$ from the edge of the MOP. In the present study, an acellular region of bone (i.e. empty lacunae) was found extending up to $0.8 \mathrm{~mm}$ from the MOP border. Acellular bone results when osteocytes undergo apoptosis in response to excessive bone strain and microfracture ${ }^{66}$ such as with insertion of a miniscrew. ${ }^{67}$ VanGemert, whose study was 
specifically designed to evaluate the extent of MOPs' effects on bone, found an acellular region extending $0.5-0.8 \mathrm{~mm}$ from the MOP border, which was closely related to the region of microfractures extending from the MOP ${ }^{64}$ They showed bone density in this region was 7 to $14 \%$ lower than in the same region on the control side. Based on quantitative differences in bone density (less than $5 \%$ difference at $1.5 \mathrm{~mm}$ ) and bone hardness (less than $1 \%$ difference at $1.5 \mathrm{~mm}$ ), they suggested that the major effects of MOPs on bone are limited to $1.5 \mathrm{~mm}$, well short of the $3 \mathrm{~mm}$ - the distance from the tooth root - required to move teeth faster in the present study.

Areas of acellular bone around the MOP site could impede tooth movements. While the control bone exhibited approximately $5 \%$ acellular bone, as previously reported for other control samples, ${ }^{66}$ acellular bone surrounded $20 \%$ to $85 \%$ of the MOP borders on the experimental side. Because osteocytes can resorb bone more efficiently from within their extensive canalicular network than osteoclasts can resorb the external surface of bone, ${ }^{68}$ the localized acellular bone may take longer to demineralize and resorb, and so serve as an impediment to tooth movement. The bone associated with the hyalinization that occurs during tooth movement is also acellular. When hyalinization occurs, tooth movement is disrupted because the necrotic areas need to be resorbed. ${ }^{69}$ Bone resorption occurs from the adjacent marrow spaces and from the unaffected PDL regions. $^{70}$

Interestingly, it appears that MOPs may produce slight, early, and temporary increases in tooth movements. In the present study, the experimental side exhibited somewhat greater - albeit not statistically significant - increases in tooth movements 
during the first few weeks. Faster tooth movements have been shown to be limited to the first month following corticotomies in other dog studies. ${ }^{42,62,71}$ Sanjideh et al, ${ }^{44}$ who perhaps most closely evaluated rates of tooth movement after corticotomies, showed maximum velocity differences during the third week, with diminishing effects thereafter. If faster tooth movements occurred in the present study, they were likely due to distant demineralization of bone. Increased osteoclastic activity up to $2.5 \mathrm{~mm}$ from the MOP site has been reported in the dog mandible after 2 weeks, but not after 4 weeks. ${ }^{64}$

In the present study, the MOPs were placed approximately $3 \mathrm{~mm}$ from the tooth being moved, which is well beyond the area of bone injured by the MOPs. In addition to attracting osteoclasts to the injured area, osteocytes serve as an interconnected network of mechanosensors that respond to local bone strain. ${ }^{72}$ Upon sensing injury, osteocytes can directly demineralize bone within their extensive canalicular network. ${ }^{68}$ Osteocytes communicate via intercellular gap junctions with over 1100 other osteocytes. ${ }^{72}$ Distant demineralization may be needed to provide calcium for local injury repair. Importantly, the slight and temporary distant demineralization that occurs does not appear to have a lasting effect on tooth movements. Moreover, slight distant demineralization may explain the difference in canine retraction produced with MOPs in humans. ${ }^{58}$ Assuming that the increase was partially due to tipping, as indicated in Figure 16 and Appendix B, the actual tooth movements could have been less than $0.8 \mathrm{~mm}$ on the experimental side and $0.3 \mathrm{~mm}$ on the control side. These values more closely approach the distant effect produced in the present study. As indicated previously, the effect is probably small and temporary, which Alikhani et a ${ }^{58}$ were not able to verify because they only evaluated 
tooth movements for 28 days; previous studies have shown increased tooth movements diminish after the first month. ${ }^{42,44,57,59,62,71}$

Considering the entire seven week duration of the present experiment, the control maxillary premolars moved less than might be expected. Caliper measurements totaled $0.9 \mathrm{~mm}$ in the present study, with approximately $0.45 \mathrm{~mm}$ per month of control tooth movement. In a systematic review, Ren and coworkers reported that dogs' teeth move $0.27 \mathrm{~mm}$ per week, or $1.08 \mathrm{~mm}$ per month. ${ }^{11}$ Their estimate was based on different types of tooth movements, including space closure between two teeth. Less movement in the present study may have resulted from better tipping control. The present appliance design limited tipping to $0.73^{\circ}$ on the control side, resulting in nearly pure bodily movement. Translation of teeth produces half as much movement as uncontrolled tipping and translation. ${ }^{73}$ Based on this ratio, the control tooth movement of $0.73 \mathrm{~mm}$ per month reported by Cho et $\mathrm{al}^{42}$ becomes $0.38 \mathrm{~mm}$ per month when tipping effects are removed, which matches the control tooth movements in the present study.

Healing time after extractions could also impact tooth movements. In the present study, extraction sites were allowed to heal for one month prior to MOP surgery and appliance activation. Hasler et a ${ }^{74}$ found that canine retraction started immediately after extractions was faster in humans than retraction after healing. Dog studies that did not allow extraction sites to heal also showed faster tooth movement ${ }^{62,71}$ than dog studies that moved teeth immediately after extraction. ${ }^{59}$ It has been suggested that extractions cause the RAP, ${ }^{75}$ during which the hard tissues undergo increased bone modeling, reduced mineral density, and transient osteopenia. ${ }^{1}$ Studies that do not control tipping 
and/or initiate tooth movement immediately after extraction will likely show faster tooth movements than the present study, which did control tipping well and allowed for extraction site healing.

Bone in the MOP site is largely, but not fully repaired after 7 weeks. At the end of the present study, the MOPs were filled with woven and some lamellar bone, suggesting that bone formation starts soon after injury. MOPs sites have been shown to exhibit small spicules of woven bone after 2 weeks, and greater amounts of woven bone and small areas of lamellar bone after 4 weeks. ${ }^{64}$ Bone around endosseous implants shows a similar healing pattern, with woven bone after 2 weeks, greater amounts of woven bone along with areas modeling into lamellar bone after 4 weeks, and woven bone nearly filling the healing chambers, along with primary and secondary osteons, after 6 weeks. During normal bone healing, injuries initially fill with a blood clot that is infiltrated within $2-3$ weeks by reparative cells to form granulation tissue, around which osteoclasts resorb the damaged bone surfaces and osteoblasts begin to deposit and rapidly mineralize osteoid on the exposed bone surface. ${ }^{40}$ Since healing depends on an adequate blood supply, the extent of injury, and the site's stability, faster healing might be expected with MOPs. With respect to MOP sites, the healing process appears to occur through direct intramembraneous bone formation, ${ }^{76}$ with woven bone appearing as soon as 2 weeks and lamellar bone appearing as early as 4 weeks, with approximately $50 \%$ woven and $50 \%$ lamellar bone by 7 weeks.

The results hold two important clinical implications. First and most important, MOPs probably do not have a clinically significant effect on tooth movements if they are 
placed away from the tooth being moved. For example, MOPs centered in an extraction site probably will no affect movements of the adjacent teeth because they are too far away and damage is insufficient. Second, if the principal effects on bone extend 1-1.5 $\mathrm{mm}$ beyond the MOPs' borders, they would need to be placed much closer to targeted teeth and in a higher numbers so as to overlap the affected areas along the surface of the tooth. Placing more MOPS closer to the tooth increases the risk of root damage, patient discomfort, and infection. In light of these concerns, patient acceptance would likely decrease. 


\section{CHAPTER VI}

\section{CONCLUSIONS}

Within the limits of this study, MOPs placed in the dentoalveolar region of dogs produced no longer-term differences in tooth movement rates and no statistically significant differences in tooth movements after 7 weeks. They also had no significant effect on the density or volume fraction of medullary bone adjacent to the tooth being moved. The MOPs may have produced slight and temporary increases in tooth movements during the first three weeks. The injury had largely repaired after 7 weeks, with woven and some lamellar bone filling the MOP site, with an acellular region of bone extending $0.8 \mathrm{~mm}$ from the MOP border. 


\section{REFERENCES}

1. Buschang PH, Campbell PM, Ruso S. Accelerating Tooth Movement With Corticotomies: Is It Possible and Desirable? Seminars in Orthodontics 2012;18:286-294.

2. Skidmore KJ, Brook KJ, Thomson WM, Harding WJ. Factors influencing treatment time in orthodontic patients. Am J Orthod Dentofacial Orthop 2006;129:230-238.

3. Beckwith FR, Ackerman RJ, Jr., Cobb CM, Tira DE. An evaluation of factors affecting duration of orthodontic treatment. Am J Orthod Dentofacial Orthop 1999;115:439-447.

4. Fisher MA, Wenger RM, Hans MG. Pretreatment characteristics associated with orthodontic treatment duration. Am J Orthod Dentofacial Orthop 2010;137:178-186.

5. Kurol J, Owman-Moll P, Lundgren D. Time-related root resorption after application of a controlled continuous orthodontic force. Am J Orthod Dentofacial Orthop 1996;110:303-310.

6. Segal GR, Schiffman PH, Tuncay OC. Meta analysis of the treatment-related factors of external apical root resorption. Orthod Craniofac Res 2004;7:71-78.

7. Artun J, Brobakken BO. Prevalence of carious white spots after orthodontic treatment with multibonded appliances. Eur J Orthod 1986;8:229-234.

8. Ristic M, Vlahovic Svabic M, Sasic M, Zelic O. Clinical and microbiological effects of fixed orthodontic appliances on periodontal tissues in adolescents. Orthod Craniofac Res 2007;10:187-195.

9. Aerssens J, Boonen S, Lowet G, Dequeker J. Interspecies differences in bone composition, density, and quality: potential implications for in vivo bone research. Endocrinology 1998;139:663-670.

10. Wang X, Mabrey JD, Agrawal CM. An interspecies comparison of bone fracture properties. Biomed Mater Eng 1998;8:1-9.

11. Ren Y, Maltha JC, Van 't Hof MA, Kuijpers-Jagtman AM. Optimum force magnitude for orthodontic tooth movement: a mathematic model. Am J Orthod Dentofacial Orthop 2004;125:71-77.

12. Cohen G, Campbell PM, Rossouw PE, Buschang PH. Effects of increased surgical trauma on rates of tooth movement and apical root resorption in foxhound dogs. Orthod Craniofac Res 2010;13:179-190. 
13. Melsen B. Tissue reaction to orthodontic tooth movement--a new paradigm. Eur J Orthod 2001;23:671-681.

14. Ren Y, Maltha JC, Kuijpers-Jagtman AM. Optimum force magnitude for orthodontic tooth movement: a systematic literature review. Angle Orthod 2003;73:86-92.

15. Boester $\mathrm{CH}$, Johnston LE. A clinical investigation of the concepts of differential and optimal force in canine retraction. Angle Orthod 1974;44:113-119.

16. Samuels RH, Rudge SJ, Mair LH. A comparison of the rate of space closure using a nickel-titanium spring and an elastic module: a clinical study. Am J Orthod Dentofacial Orthop 1993;103:464-467.

17. Samuels RH, Rudge SJ, Mair LH. A clinical study of space closure with nickeltitanium closed coil springs and an elastic module. Am J Orthod Dentofacial Orthop 1998;114:73-79.

18. Iwasaki LR, Haack JE, Nickel JC, Morton J. Human tooth movement in response to continuous stress of low magnitude. Am J Orthod Dentofacial Orthop 2000;117:175183.

19. Nightingale C, Jones SP. A clinical investigation of force delivery systems for orthodontic space closure. J Orthod 2003;30:229-236.

20. Daskalogiannakis J, McLachlan KR. Canine retraction with rare earth magnets: an investigation into the validity of the constant force hypothesis. Am J Orthod Dentofacial Orthop 1996;109:489-495.

21. Burrow SJ. Canine retraction rate with self-ligating brackets vs conventional edgewise brackets. Angle Orthod 2010;80:438-445.

22. Owens SE, Buschang PH, Cope JB, Franco PF, Rossouw PE. Experimental evaluation of tooth movement in the beagle dog with the mini-screw implant for orthodontic anchorage. Am J Orthod Dentofacial Orthop 2007;132:639-646.

23. Pilon JJ, Kuijpers-Jagtman AM, Maltha JC. Magnitude of orthodontic forces and rate of bodily tooth movement. An experimental study. Am J Orthod Dentofacial Orthop 1996;110:16-23.

24. van Leeuwen EJ, Maltha JC, Kuijpers-Jagtman AM. Tooth movement with light continuous and discontinuous forces in beagle dogs. Eur J Oral Sci 1999;107:468-474.

25. Gross D, Williams WS. Streaming potential and the electromechanical response of physiologically-moist bone. J Biomech 1982;15:277-295. 
26. Davidovitch Z, Finkelson MD, Steigman S, Shanfeld JL, Montgomery PC, Korostoff E. Electric currents, bone remodeling, and orthodontic tooth movement. II. Increase in rate of tooth movement and periodontal cyclic nucleotide levels by combined force and electric current. Am J Orthod 1980;77:33-47.

27. Bassett CA, Becker RO. Generation of electric potentials by bone in response to mechanical stress. Science 1962;137:1063-1064.

28. Burger EH, Klein-Nulend J. Mechanotransduction in bone--role of the lacunocanalicular network. Faseb j 1999;13 Suppl:S101-112.

29. Moss ML. The functional matrix hypothesis revisited. 1. The role of mechanotransduction. Am J Orthod Dentofacial Orthop 1997;112:8-11.

30. Moss ML. The functional matrix hypothesis revisited. 2. The role of an osseous connected cellular network. Am J Orthod Dentofacial Orthop 1997;112:221-226.

31. Bister D, Meikle MC. Re-examination of 'Einige Beiträge zur Theorie der Zahnregulierung' (Some contributions to the theory of the regulation of teeth) published in 1904-1905 by Carl Sandstedt. European Journal of Orthodontics 2013;35:160-168.

32. Oppenheim A. Tissue changes, particularly of the bone, incident to tooth movement. European Journal of Orthodontics 2007;29:i2-i15.

33. Schwarz AM. Tissue changes incidental to orthodontic tooth movement. International Journal of Orthodontia, Oral Surgery and Radiography 1932;18:331-352.

34. King GJ, Keeling SD, Wronski TJ. Histomorphometric study of alveolar bone turnover in orthodontic tooth movement. Bone 1991;12:401-409.

35. Verna C, Dalstra M, Melsen B. The rate and the type of orthodontic tooth movement is influenced by bone turnover in a rat model. Eur J Orthod 2000;22:343-352.

36. Goldie RS, King GJ. Root resorption and tooth movement in orthodontically treated, calcium-deficient, and lactating rats. Am J Orthod 1984;85:424-430.

37. Ashcraft MB, Southard KA, Tolley EA. The effect of corticosteroid-induced osteoporosis on orthodontic tooth movement. Am J Orthod Dentofacial Orthop 1992;102:310-319.

38. Frost HM. The regional acceleratory phenomenon: a review. Henry Ford Hosp Med J 1983;31:3-9. 
39. Frost HM. The biology of fracture healing. An overview for clinicians. Part II. Clin Orthop Relat Res 1989:294-309.

40. Frost HM. The biology of fracture healing. An overview for clinicians. Part I. Clin Orthop Relat Res 1989:283-293.

41. Wilcko WM, Wilcko T, Bouquot JE, Ferguson DJ. Rapid orthodontics with alveolar reshaping: two case reports of decrowding. Int J Periodontics Restorative Dent 2001;21:9-19.

42. Cho KW, Cho SW, Oh CO, Ryu YK, Ohshima H, Jung HS. The effect of cortical activation on orthodontic tooth movement. Oral Dis 2007;13:314-319.

43. Iino S, Sakoda S, Ito G, Nishimori T, Ikeda T, Miyawaki S. Acceleration of orthodontic tooth movement by alveolar corticotomy in the dog. Am J Orthod Dentofacial Orthop 2007;131:448 e441-448.

44. Sanjideh PA, Rossouw PE, Campbell PM, Opperman LA, Buschang PH. Tooth movements in foxhounds after one or two alveolar corticotomies. Eur J Orthod 2010;32:106-113.

45. McBride MD, Campbell PM, Opperman LA, Dechow PC, Buschang PH. How does the amount of surgical insult affect bone around moving teeth? Am J Orthod Dentofacial Orthop 2014;145:S92-99.

46. Sebaoun JD, Kantarci A, Turner JW, Carvalho RS, Van Dyke TE, Ferguson DJ. Modeling of trabecular bone and lamina dura following selective alveolar decortication in rats. J Periodontol 2008;79:1679-1688.

47. Schlee M, Steigmann M, Bratu E, Garg AK. Piezosurgery: basics and possibilities. Implant Dent 2006;15:334-340.

48. Swapp A, Campbell PM, Spears R, Buschang PH. Flapless cortical bone damage has no effect on medullary bone mesial to teeth being moved. Am J Orthod Dentofacial Orthop 2015;147:547-558.

49. Kim SJ, Park YG, Kang SG. Effects of Corticision on paradental remodeling in orthodontic tooth movement. Angle Orthod 2009;79:284-291.

50. Dibart S, Sebaoun JD, Surmenian J. Piezocision: a minimally invasive, periodontally accelerated orthodontic tooth movement procedure. Compend Contin Educ Dent 2009;30:342-344, 346, 348-350. 
51. Dibart S, Surmenian J, Sebaoun JD, Montesani L. Rapid treatment of Class II malocclusion with piezocision: two case reports. Int J Periodontics Restorative Dent 2010;30:487-493.

52. Keser EI, Dibart S. Sequential piezocision: a novel approach to accelerated orthodontic treatment. Am J Orthod Dentofacial Orthop 2013;144:879-889.

53. Dibart S, Yee C, Surmenian J, Sebaoun JD, Baloul S, Goguet-Surmenian E et al. Tissue response during Piezocision-assisted tooth movement: a histological study in rats. Eur J Orthod 2014;36:457-464.

54. Ruso S, Campbell PM, Rossmann J, Opperman LA, Taylor RW, Buschang PH. Bone response to buccal tooth movements--with and without flapless alveolar decortication. Eur J Orthod 2013.

55. Kim YS, Kim SJ, Yoon HJ, Lee PJ, Moon W, Park YG. Effect of piezopuncture on tooth movement and bone remodeling in dogs. Am J Orthod Dentofacial Orthop 2013;144:23-31.

56. Teixeira CC, Khoo E, Tran J, Chartres I, Liu Y, Thant LM et al. Cytokine expression and accelerated tooth movement. J Dent Res 2010;89:1135-1141.

57. Baloul SS, Gerstenfeld LC, Morgan EF, Carvalho RS, Van Dyke TE, Kantarci A. Mechanism of action and morphologic changes in the alveolar bone in response to selective alveolar decortication-facilitated tooth movement. Am J Orthod Dentofacial Orthop 2011;139:S83-101.

58. Alikhani M, Raptis M, Zoldan B, Sangsuwon C, Lee YB, Alyami B et al. Effect of micro-osteoperforations on the rate of tooth movement. Am J Orthod Dentofacial Orthop 2013;144:639-648.

59. Kim SJ, Moon SU, Kang SG, Park YG. Effects of low-level laser therapy after Corticision on tooth movement and paradental remodeling. Lasers Surg Med 2009;41:524-533.

60. Owen K. Elevation of a Full-thickness Mucoperiosteal Flap Alone Accelerates Orthodontic Tooth Movement. A Thesis. 2015.

61. Yaffe A, Fine N, Binderman I. Regional accelerated phenomenon in the mandible following mucoperiosteal flap surgery. J Periodontol 1994;65:79-83.

62. Safavi SM, Heidarpour M, Izadi SS, Heidarpour M. Effects of flapless bur decortications on movement velocity of dogs' teeth. Dent Res J (Isfahan) 2012;9:783789. 
63. Melsen B. Biological reaction of alveolar bone to orthodontic tooth movement. Angle Orthod 1999;69:151-158.

64. VanGemert L. Localization of the osseous boundaries of the regional acceleratory phenomenon. Masters thesis in progress. 2016.

65. PROPEL. Propel Accelerated Orthodontics. https://www.youtube.com/watch?v=D76-n3SO43w; 2014.

66. Verborgt O, Gibson GJ, Schaffler MB. Loss of osteocyte integrity in association with microdamage and bone remodeling after fatigue in vivo. J Bone Miner Res 2000;15:6067.

67. Liu SS, Cruz-Marroquin E, Sun J, Stewart KT, Allen MR. Orthodontic mini-implant diameter does not affect in-situ linear microcrack generation in the mandible or the maxilla. Am J Orthod Dentofacial Orthop 2012;142:768-773.

68. Nango N, Kubota S, Hasegawa T, Yashiro W, Momose A, Matsuo K. Osteocytedirected bone demineralization along canaliculi. Bone 2015;84:279-288.

69. Cardaropoli D GL. The Influence of Orthodontic Movement on Periodontal Tissues Level. Seminars in Orthodontics 2007;13:234-245.

70. Krishnan V, Davidovitch Z. On a path to unfolding the biological mechanisms of orthodontic tooth movement. J Dent Res 2009;88:597-608.

71. Mostafa YA, Mohamed Salah Fayed M, Mehanni S, ElBokle NN, Heider AM. Comparison of corticotomy-facilitated vs standard tooth-movement techniques in dogs with miniscrews as anchor units. Am J Orthod Dentofacial Orthop 2009;136:570-577.

72. Buenzli PR, Sims NA. Quantifying the osteocyte network in the human skeleton. Bone 2015;75:144-150.

73. Nakano T, Hotokezaka H, Hashimoto M, Sirisoontorn I, Arita K, Kurohama T et al. Effects of different types of tooth movement and force magnitudes on the amount of tooth movement and root resorption in rats. Angle Orthod 2014;84:1079-1085.

74. Hasler R, Schmid G, Ingervall B, Gebauer U. A clinical comparison of the rate of maxillary canine retraction into healed and recent extraction sites--a pilot study. Eur $\mathrm{J}$ Orthod 1997;19:711-719.

75. Verna C. Regional Acceleratory Phenomenon. Front Oral Biol 2016;18:28-35. 
76. Loi F, Cordova LA, Pajarinen J, Lin TH, Yao Z, Goodman SB. Inflammation, fracture and bone repair. Bone 2016.

77. Ash MM NS. Wheeler's Dental Anatomy, Physiology, and Occlusion 2003:196.

78. Burstone CJ, Pryputniewicz RJ. Holographic determination of centers of rotation produced by orthodontic forces. Am J Orthod 1980;77:396-409. 


\section{APPENDIX A}

\section{FIGURES}

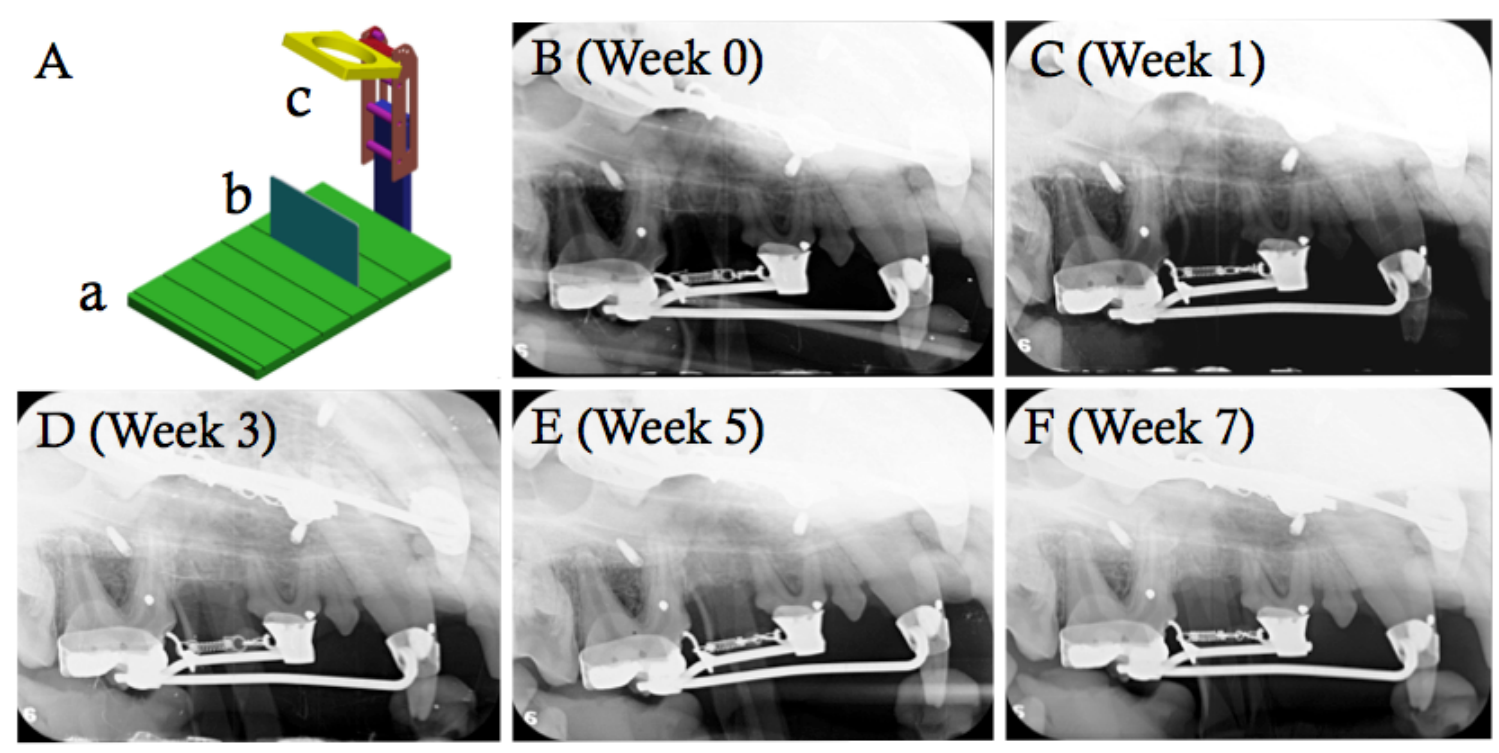

Figure 1: Cephalostat diagram and a series of radiographs. Panel A shows the dog cephalostat with baseplate (a), occlusal plate (b), X-Ray tube holder (c). Panels B through F show a series of radiographs from Week 0 to Week 7 for one dog.

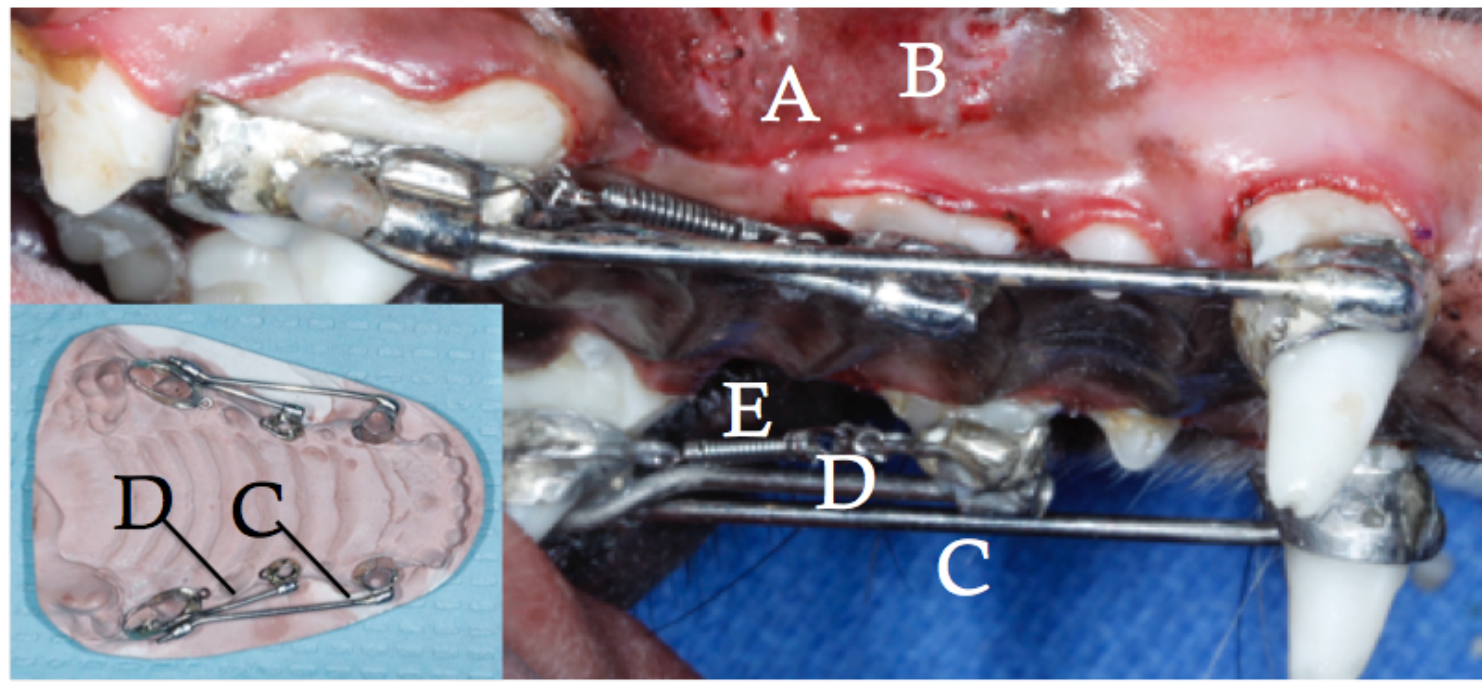

Figure 2. Appliance design and MOP placement. A - Distal MOP Field, B - Furcation MOPs, C - SST Guard Wire, D - SST Guide Wire, E - 200g NiTi Closed Coil Spring 


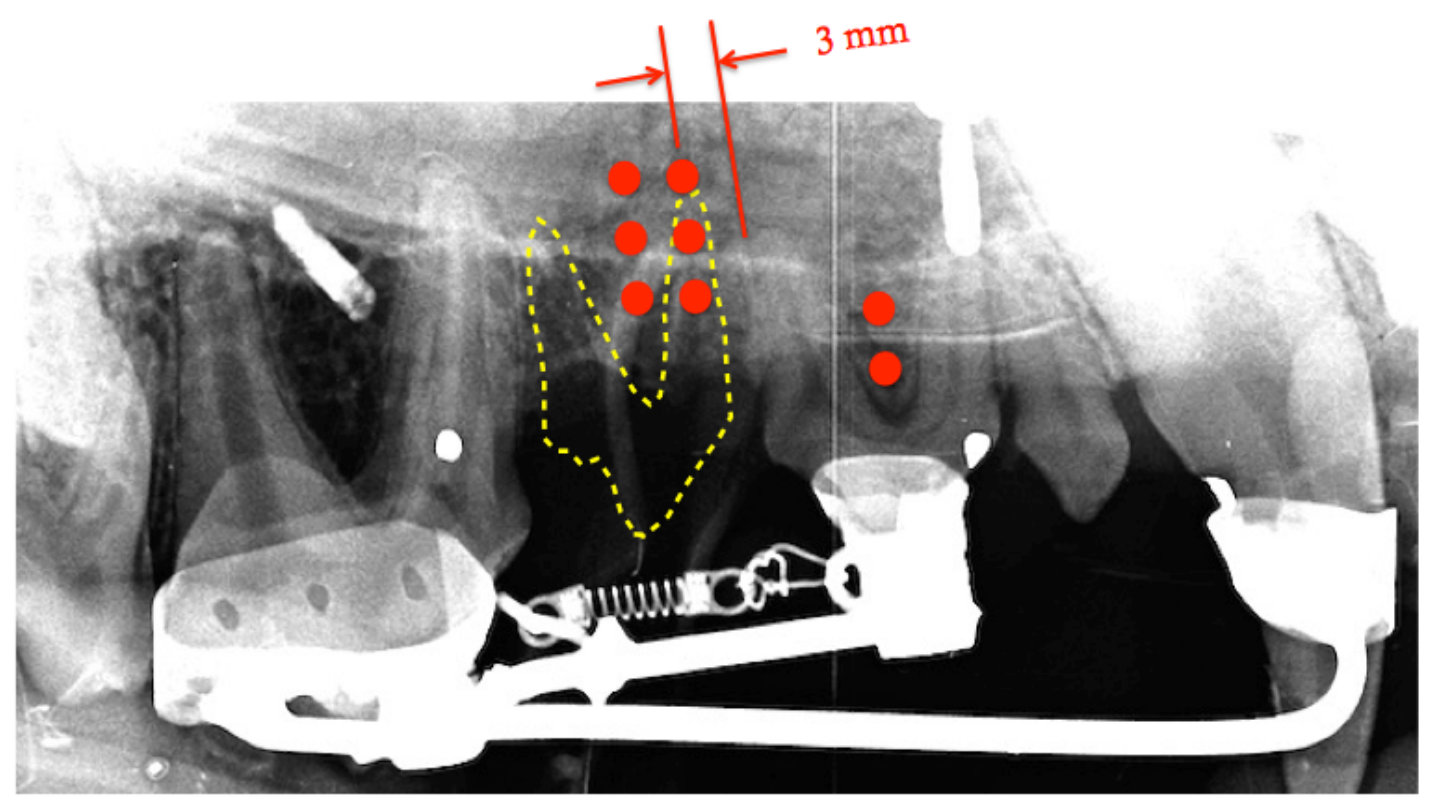

Figure 3. Radiographic MOP placement. Red dots represent $1.5 \mathrm{~mm}$ diameter x $7 \mathrm{~mm}$ deep MOPs.

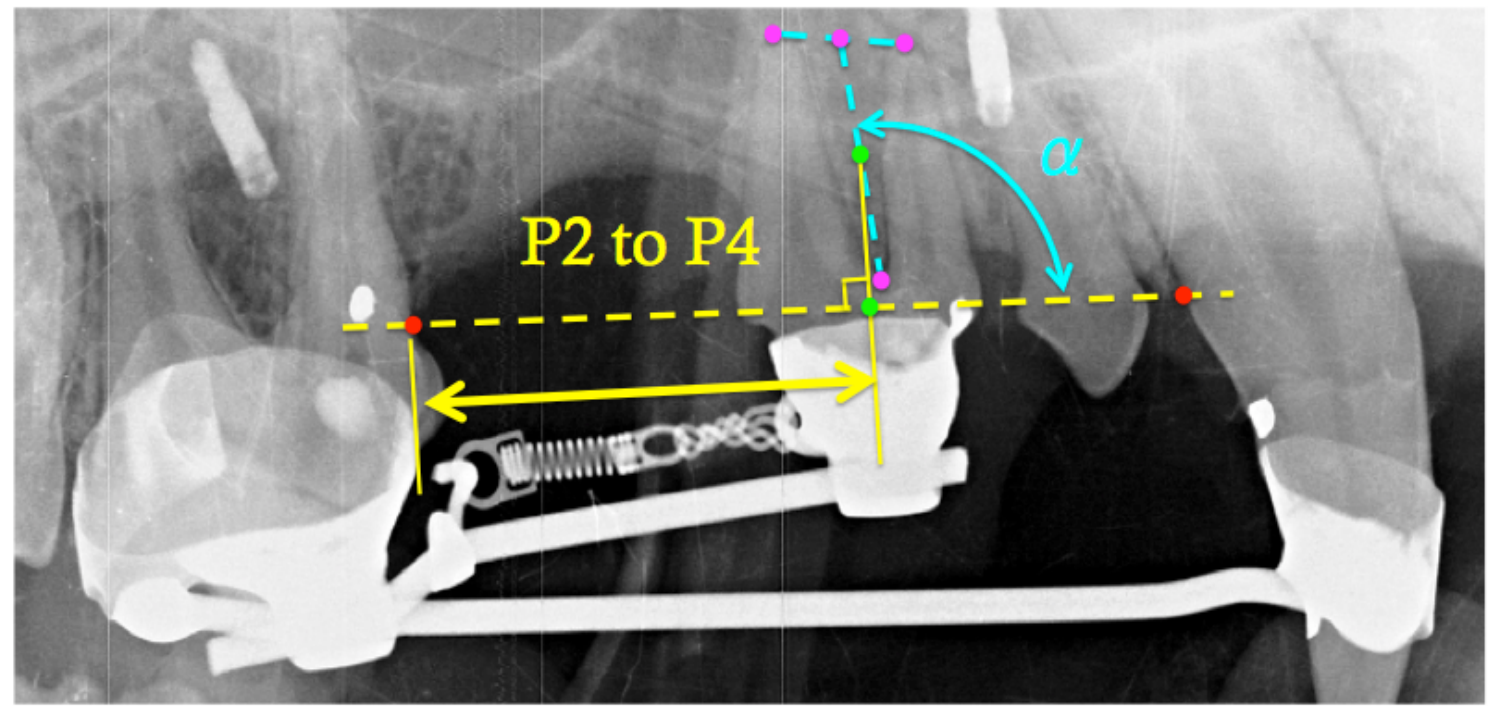

Figure 4. Radiographic analysis points and dimensions. 


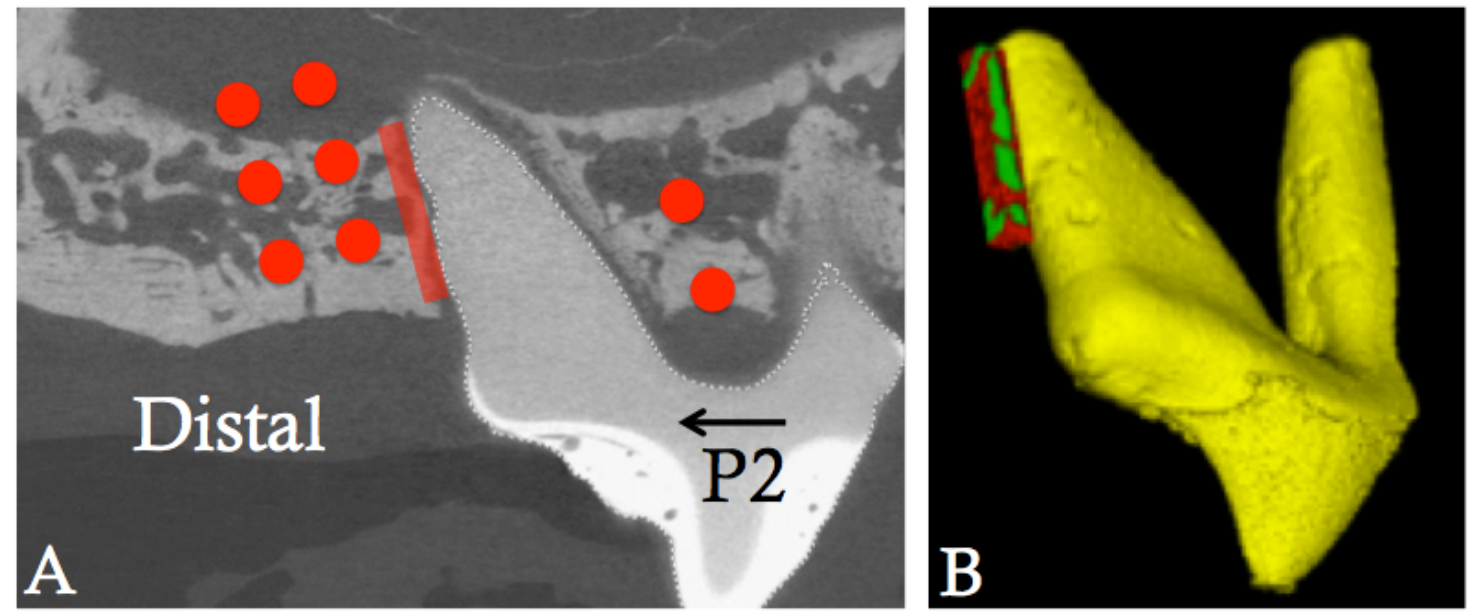

Figure 5: MOP locations and $\mu \mathrm{CT}$ volume of interest. Panel A shows $\mu \mathrm{CT}$ volume of interest (red rectangle) and MOP locations (red dots). Panel B shows 3D volume of interest. Red dots represent $1.5 \mathrm{~mm}$ diameter $\mathrm{x} 7 \mathrm{~mm}$ deep MOPs.

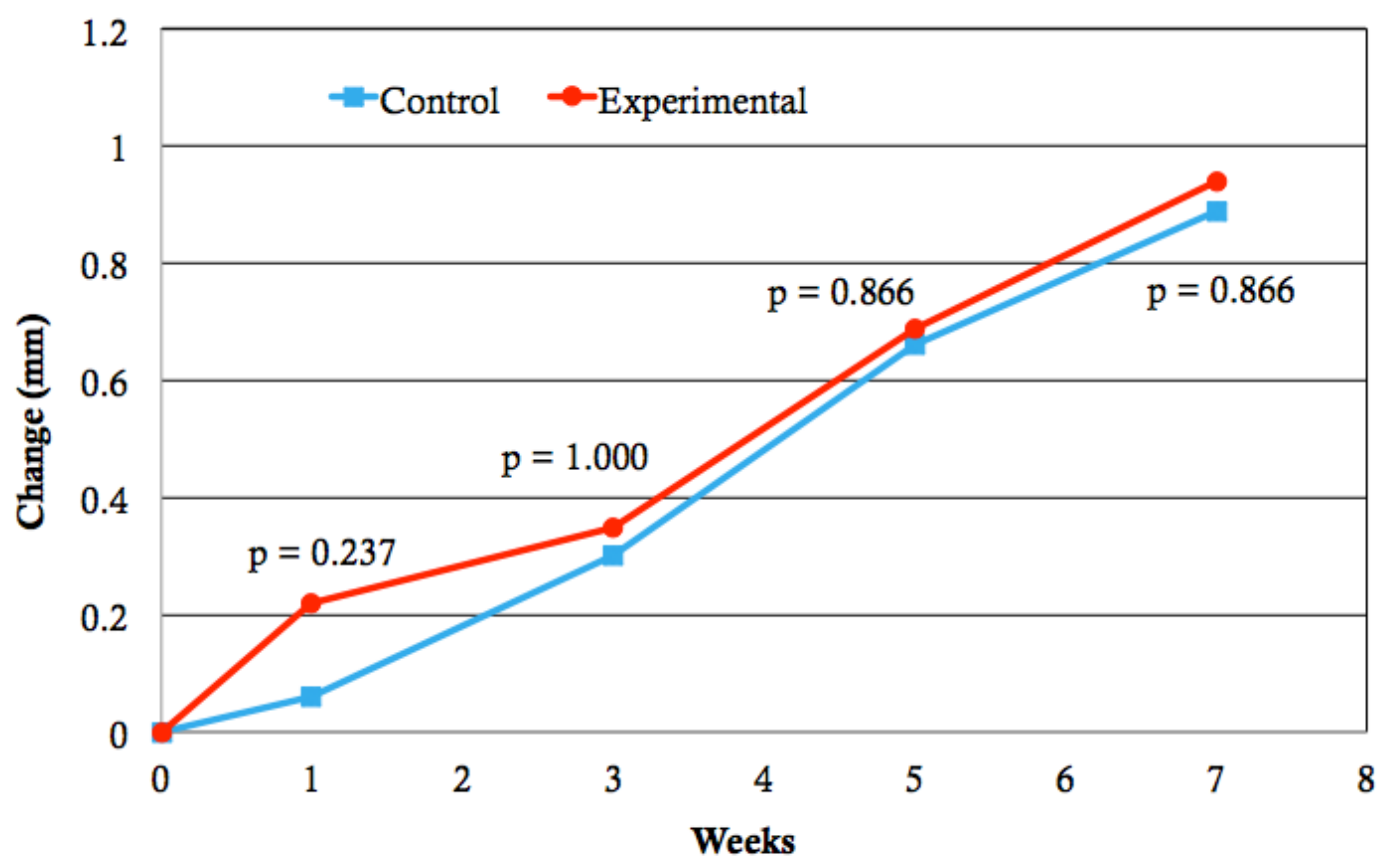

Figure 6: Intraoral caliper measurements of P2-P4 space closure. 


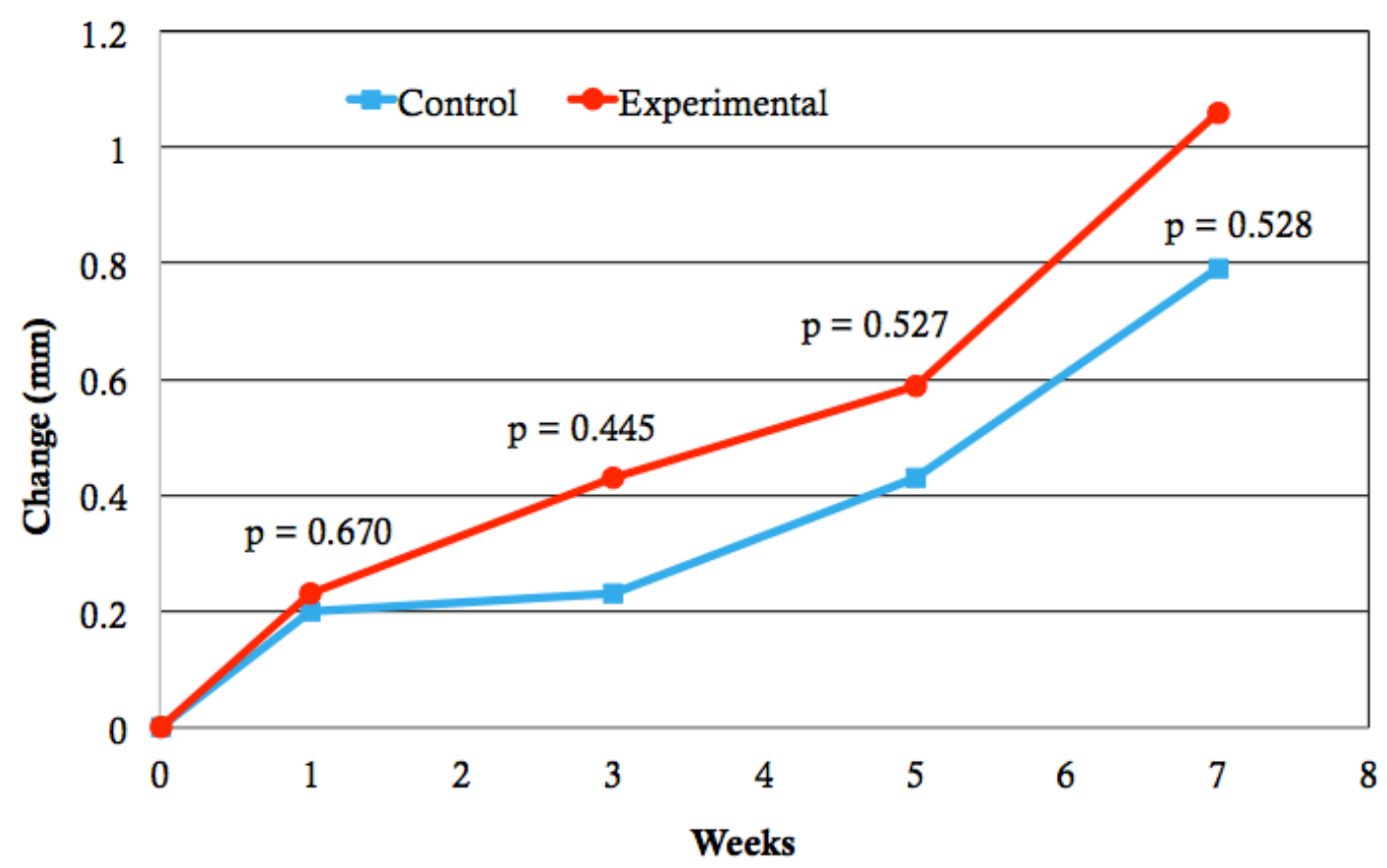

Figure 7: Radiographic measurements of P2-P4 space closure.

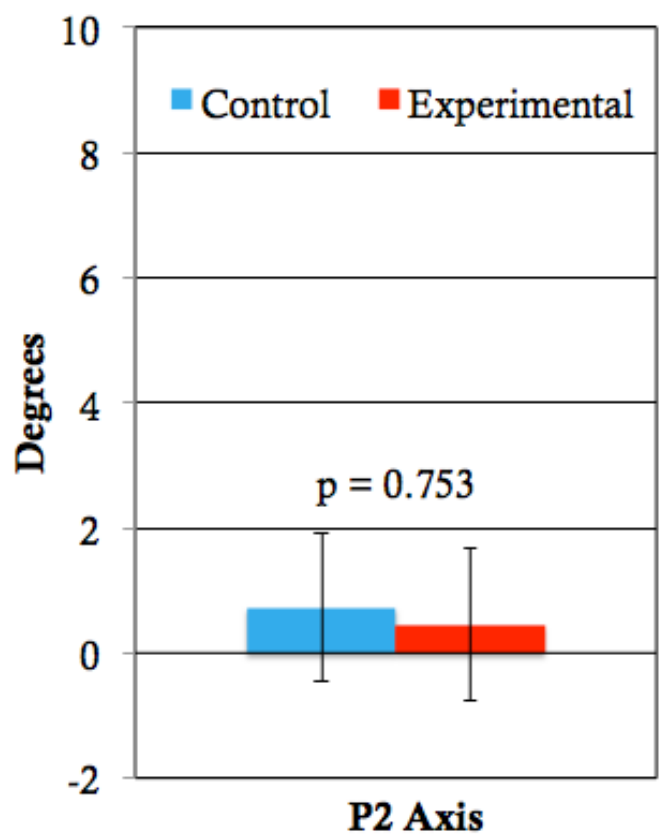

Figure 8: Tipping of P2 axis. 


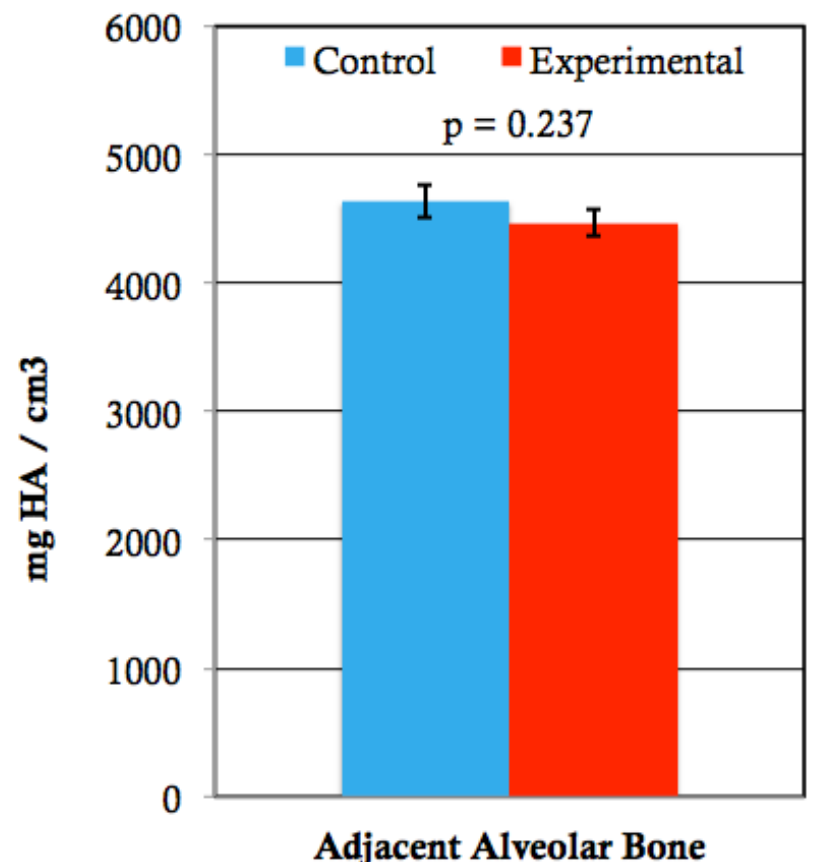

Figure 9: Adjacent alveolar bone density.

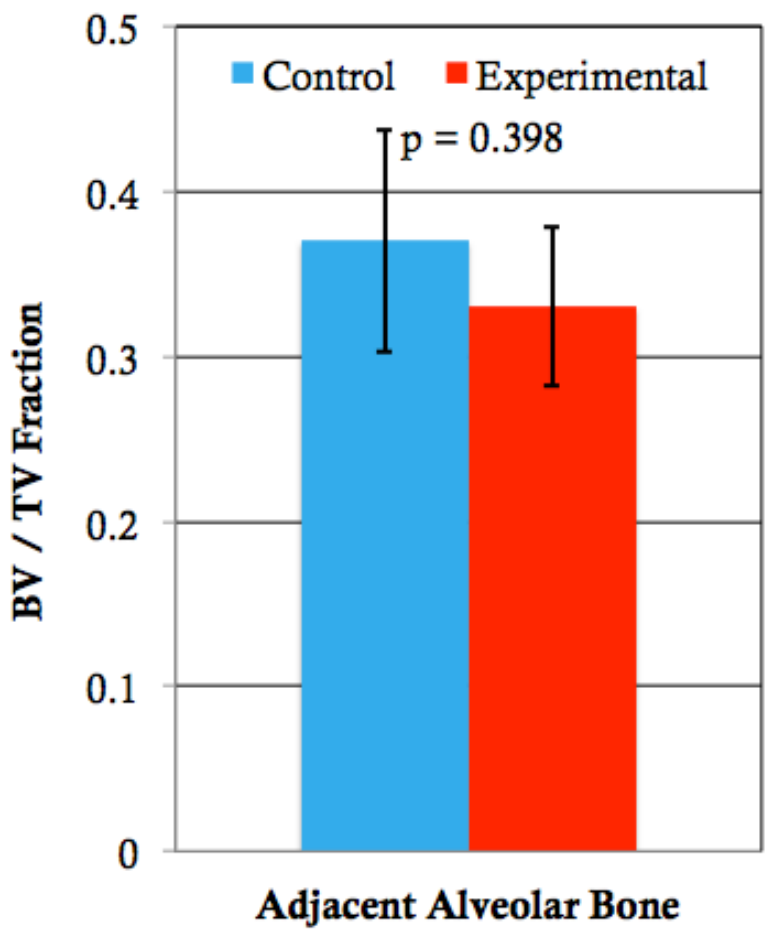

Figure 10: Adjacent alveolar bone volume fraction (BV/TV). 

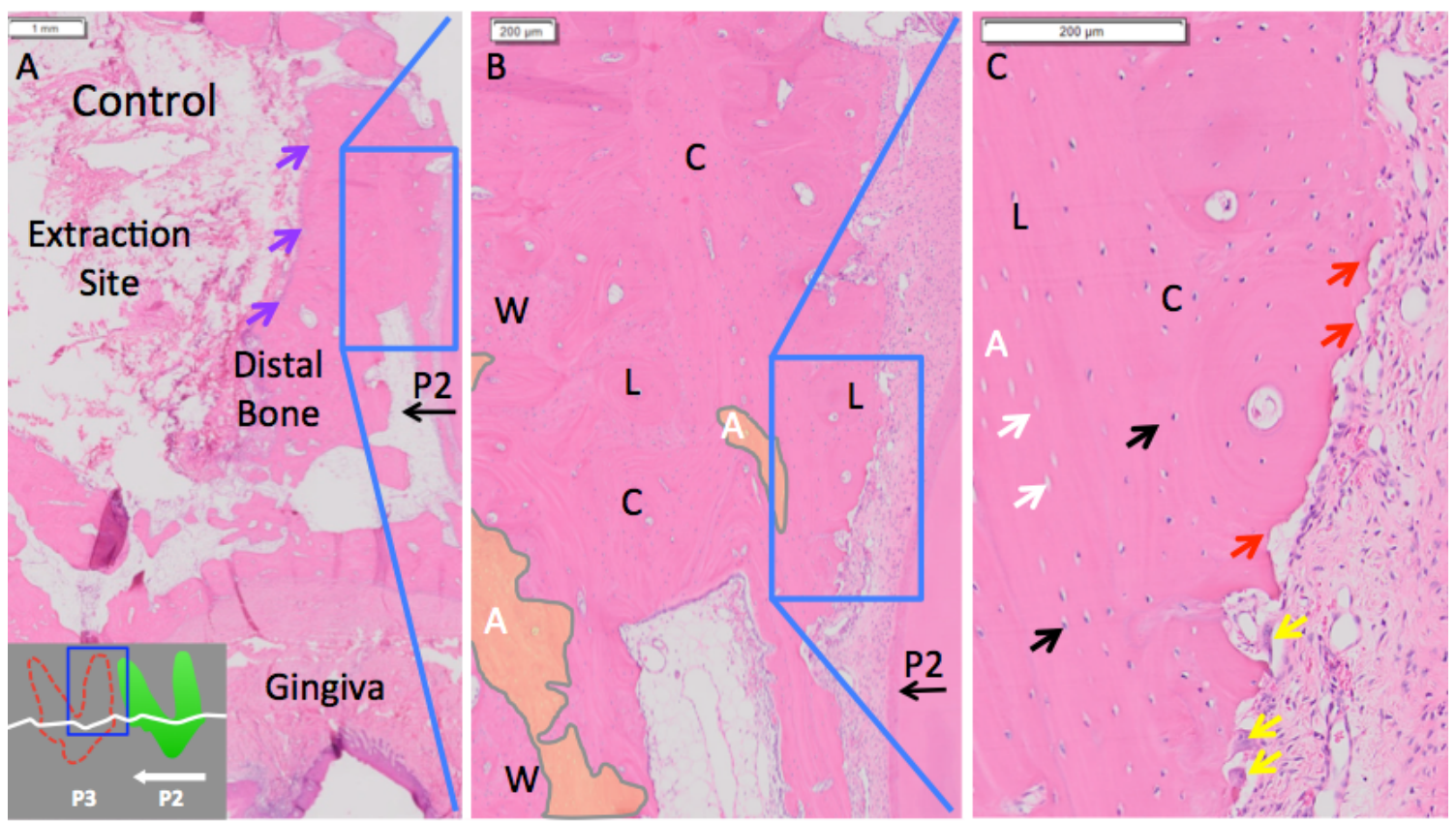

Figure 11: Control side $\mathrm{H}+\mathrm{E}$ sections. Purple arrows = woven bone adjacent to extraction site. White arrows = empty lacunae. Black arrows = lacunae with osteocytes. Yellow arrows $=$ osteoclasts. Red arrows $=$ vacated Howship's lacunae. $\mathrm{C}=$ cellular bone. $\mathrm{A}=$ acellular bone. $\mathrm{W}=$ woven bone. $\mathrm{L}=$ lamellar bone. $\mathrm{P} 2=$ second premolar.
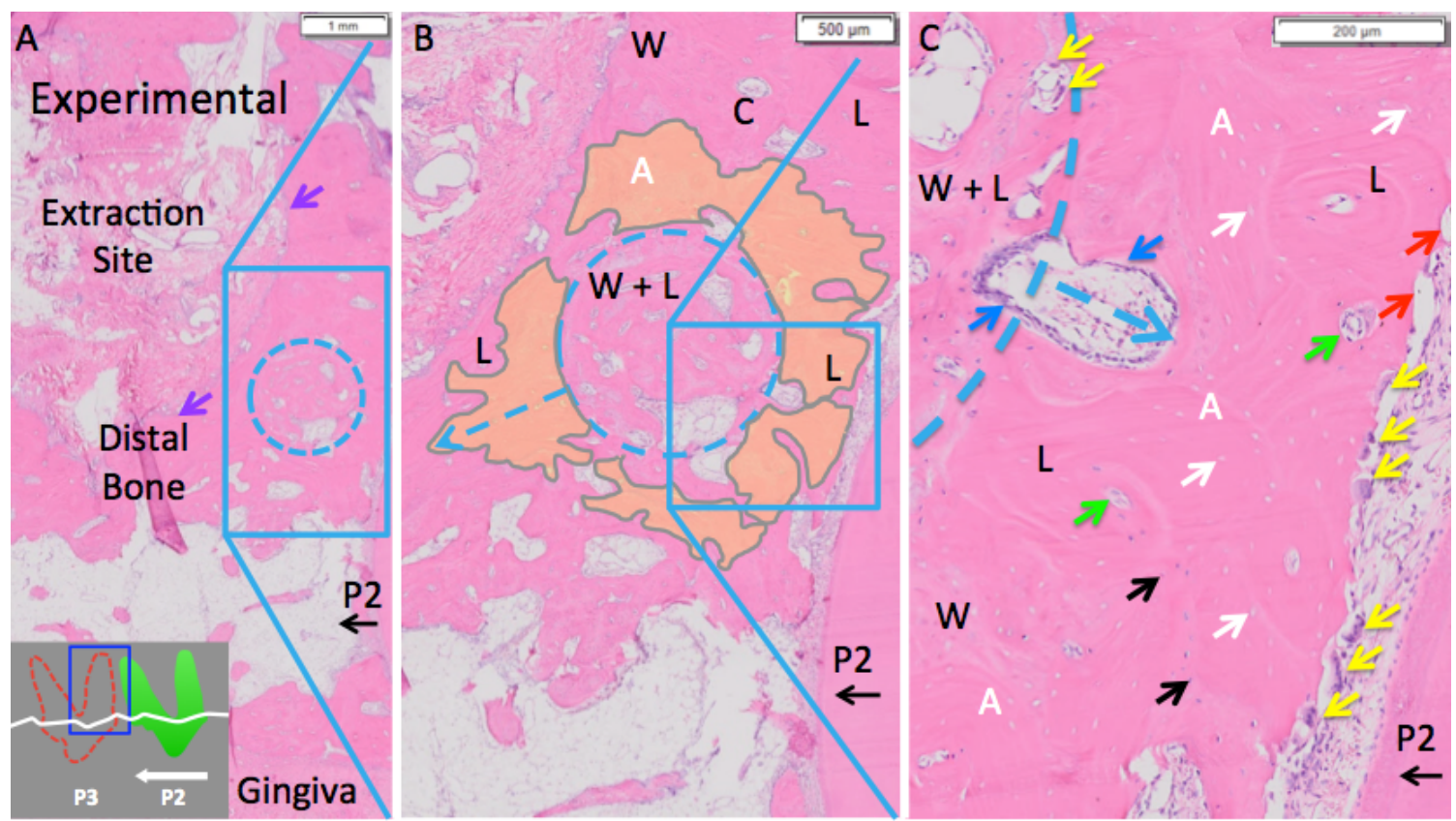

Figure 12: Experimental side $\mathrm{H}+\mathrm{E}$ sections. Purple arrows $=$ woven bone adjacent to extraction site. White arrows = empty lacunae. Black arrows $=$ lacunae with osteocytes. Green arrows $=$ active Haversian canals. Blue arrows = osteoblasts. Yellow arrows $=$ osteoclasts. Red arrows $=$ vacated Howship's lacunae. $\mathrm{C}=$ cellular bone. $\mathrm{A}=$ acellular bone. $\mathrm{W}=$ woven bone. $\mathrm{L}=$ lamellar bone. $\mathrm{P} 2$ = second premolar. 


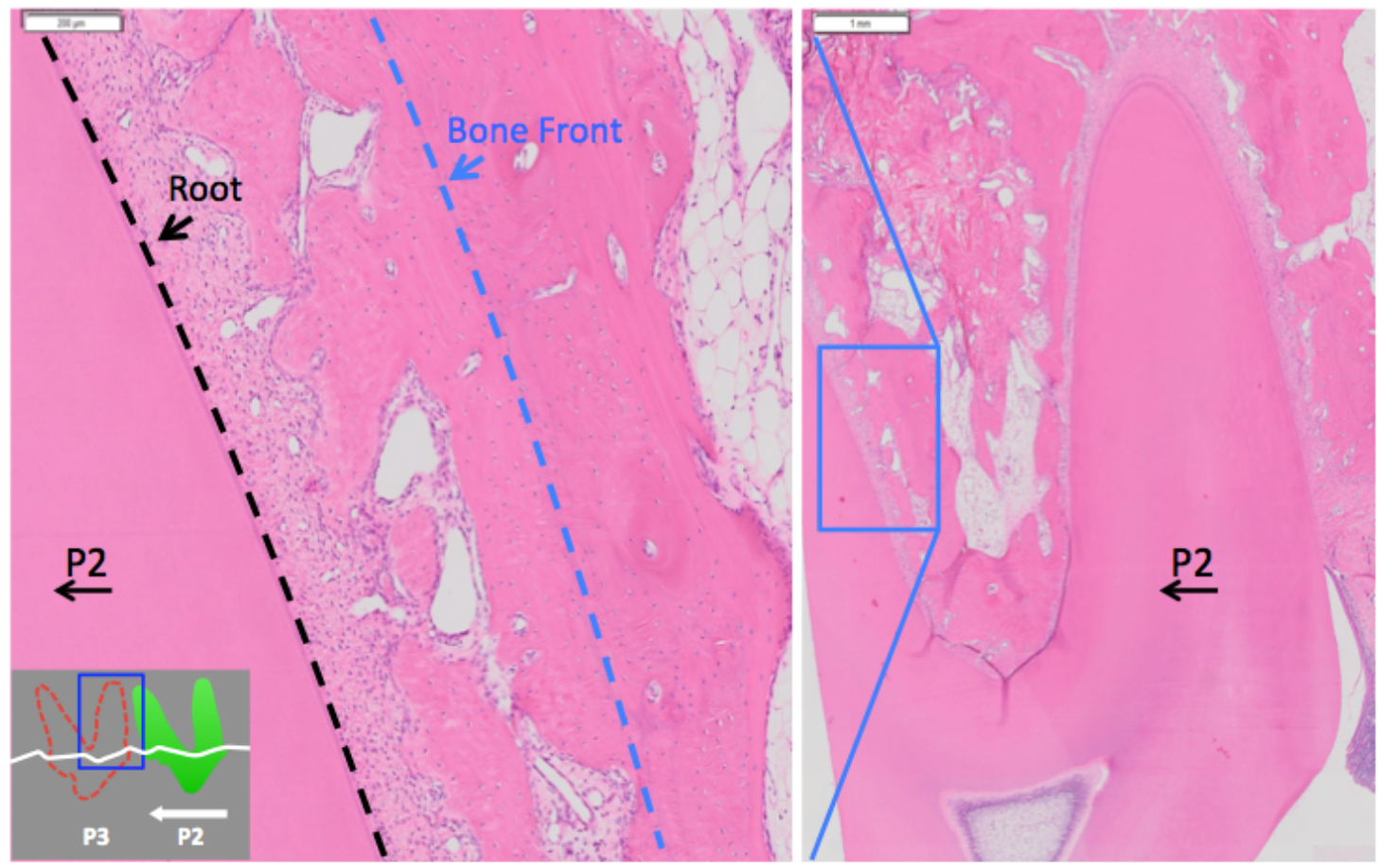

Figure 13: Control side second premolar with magnification of bone front.

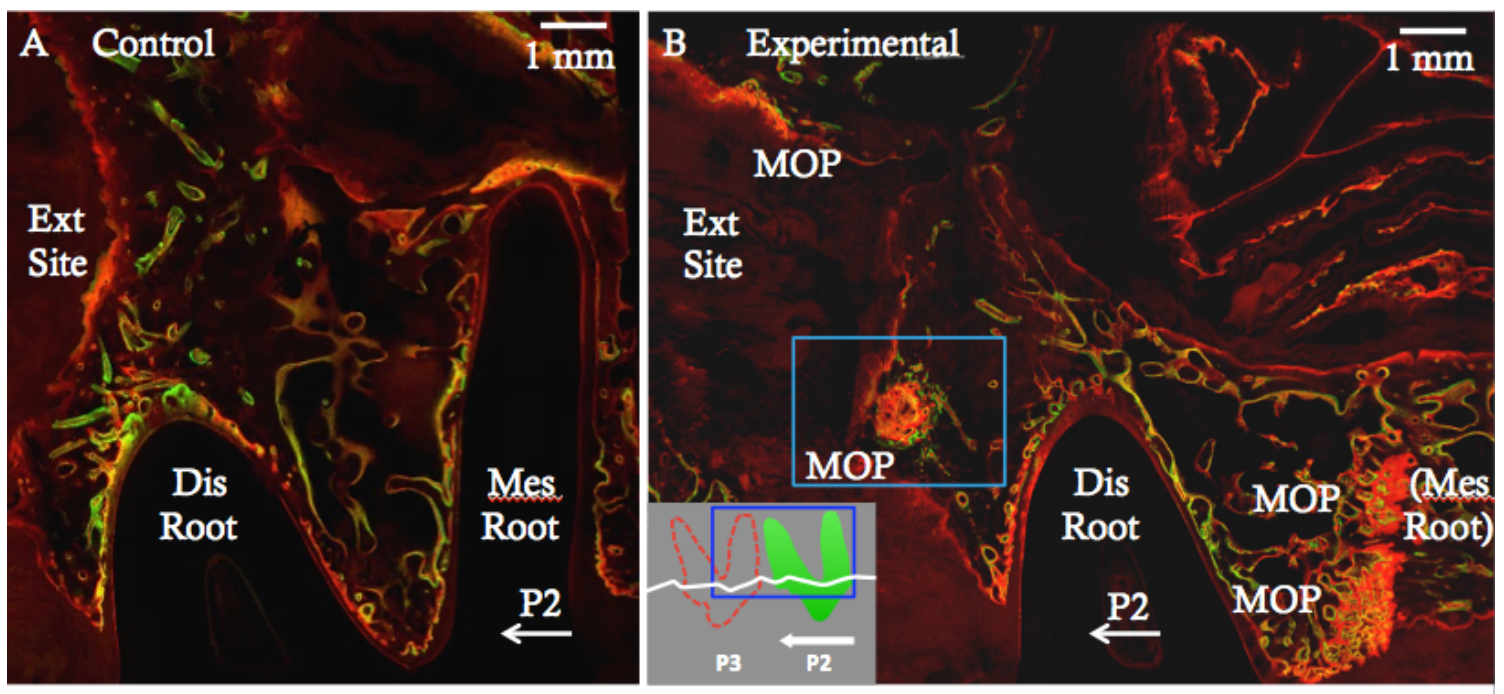

Figure 14: Control and experimental fluorescent sections. 


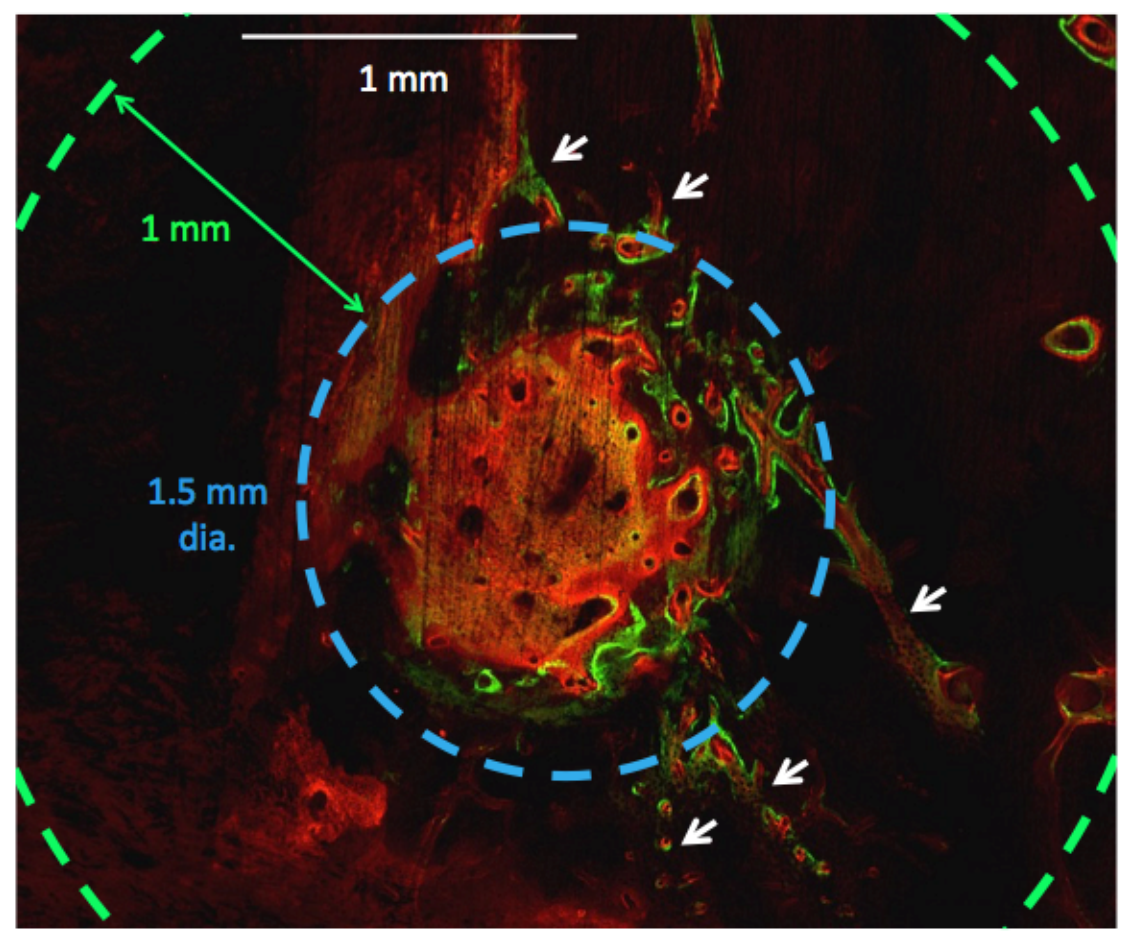

Figure 15: Magnified MOP fluorescent section. White arrows = possible microfractures undergoing repair

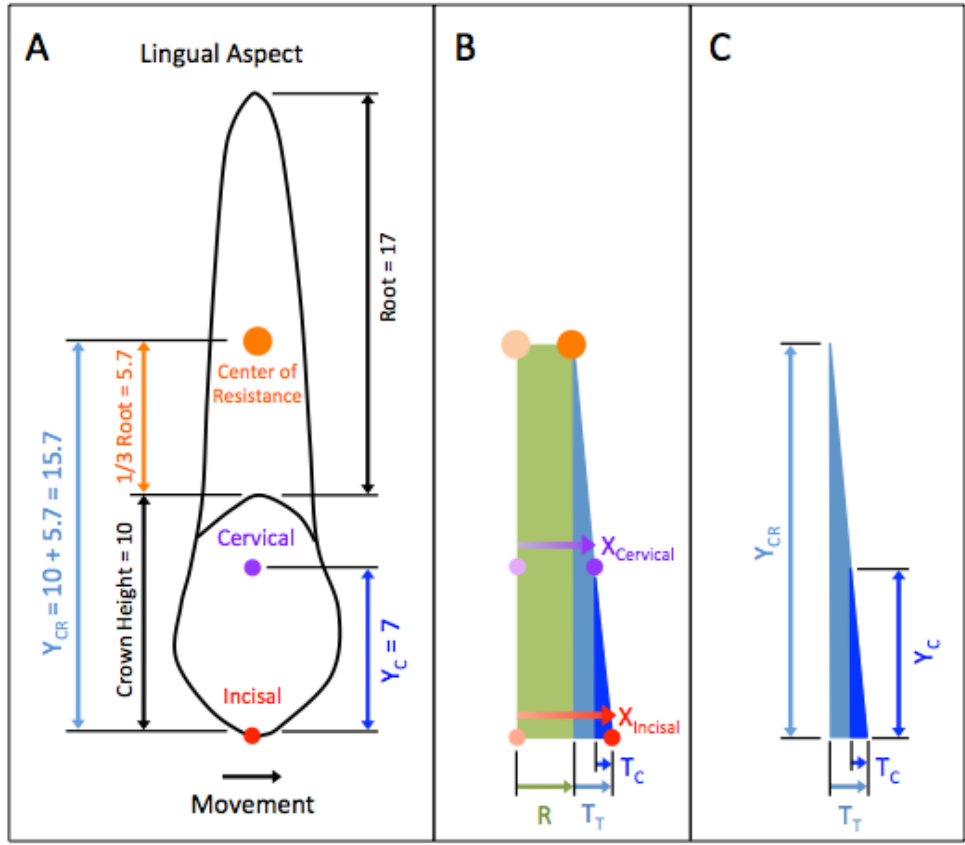

Figure 16: Tipping calculation for Mx Canine. See Appendix B for detailed calculations. Values are approximate. 


\section{APPENDIX B}

\section{MAXILLARY CANINE TIPPING CALCULATION}

Tip results in the tooth's incisal edge cusp tip moving further than the tooth's center of resistance. Based on the provided measurements, tip can be estimated for the reported maxillary canine movement in Alikhani et al. ${ }^{58}$ The incisal and cervical measurement points and movements are represented in Figure 16. Panel A shows the estimated crown height, ${ }^{77}$ root length, ${ }^{77}$ center of resistance location, ${ }^{78}$ and vertical height from the incisal edge to the cervix ${ }^{77}$ represented as $\mathrm{Y}_{\mathrm{C}}$; these values represent a typical maxillary canine morphology. Also shown in panel $\mathrm{A}, \mathrm{Y}_{\mathrm{CR}}$ represents the total tooth height from the center of resistance to the incisal edge, which can be estimated as follows:

$Y_{C R}=$ Crown Height $+\frac{1}{3} *$ Root Length

Figure 16 panel B illustrates the maxillary canine's bodily translation $(\mathrm{R})$ of the center of resistance and total tipping of the tooth $\left(\mathrm{T}_{\mathrm{T}}\right)$. $\mathrm{X}_{\text {Cervical }}$ and $\mathrm{X}_{\text {Incisal }}$ represent the measured movements of the tooth's cervix and the incisal cusp, respectively. The difference between these values equals $\mathrm{T}_{\mathrm{C}}$, the amount of tip in the clinical crown:

$T_{C}=X_{\text {Incisal }}-X_{\text {Cervical }}$ 
As seen in Figure 16 Panel C, similar triangles relate the tooth's incisal and cervical movements to the center of resistance. The following ratio therefore relates the estimated total tooth tipping, $\mathrm{T}_{\mathrm{T}}$, which occurs from the center of resistance to the cusp tip, and the tip in the clinical crown, $\mathrm{T}_{\mathrm{C}}$ :

$\frac{T_{T}}{T_{C}}=\frac{Y_{C R}}{Y_{C}}$

Solving this ratio for $\mathrm{T}_{\mathrm{T}}$ yields:

$T_{T}=\frac{Y_{C R}}{Y_{C}} * T_{C}$

As shown in Panel B, the measured incisal movement, $\mathrm{X}_{\text {Incisal, }}$ can be related to the tooth's bodily translation, $\mathrm{R}$, and total tip, $\mathrm{T}_{\mathrm{T}}$, through the following equation:

$X_{\text {Incisal }}=R+T_{T}$

Rearranging this relationship gives:

$R=X_{\text {Incisal }}-T_{T}$ 
Therefore the tooth's bodily translation, $\mathrm{R}$, and the tooth's total tipping, $\mathrm{T}_{\mathrm{T}}$, can be estimated from the Alikhani et al data using the above equations. Calculations for variables common to both the control and experimental sides follow:

Crown Height $=10 \mathrm{~mm}$

Root Length $=17 \mathrm{~mm}$

$Y_{C R}=$ Crown Height $+\frac{1}{3} *$ Root Length $=10+\frac{1}{3} * 17=15.7 \mathrm{~mm}$

$Y_{C}=7 \mathrm{~mm}$

Translation and tipping calculations specific to control side follow:

$T_{C}=X_{\text {Incisal }}-X_{\text {Cervical }}=0.55-0.43=0.12 \mathrm{~mm}$

$T_{T}=\frac{Y_{C R}}{Y_{C}} * T_{C}=\frac{15.7}{7} * 0.12=0.27 \mathrm{~mm}$

$R=X_{\text {Incisal }}-T_{T}=0.55-0.27=0.28 \mathrm{~mm}$

Similarly for the experimental side, translation and tipping calculations can be made as follows:

$$
\begin{aligned}
& T_{C}=X_{\text {Incisal }}-X_{\text {Cervical }}=1.27-1.05=0.22 \mathrm{~mm} \\
& T_{T}=\frac{Y_{C R}}{Y_{C}} * T_{C}=\frac{15.7}{7} * 0.22=0.49 \mathrm{~mm}
\end{aligned}
$$


$R=X_{\text {Incisal }}-T_{T}=1.27-0.49=0.78 \mathrm{~mm}$

The above calculations indicate that the $0.55 \mathrm{~mm}$ reported for the control side incisal measurement resulted from an estimated $0.28 \mathrm{~mm}$ of bodily translation and 0.27 $\mathrm{mm}$ of tip. For the experimental side, the reported $1.27 \mathrm{~mm}$ of incisal movement resulted from an estimated bodily translation of $0.78 \mathrm{~mm}$ and tipping of $0.49 \mathrm{~mm}$. 